\title{
Syntheses of Methyl Jasmonate and Analogues
}

\author{
Christian Chapuis*, David Skuy, and Claude-Alain Richard
}

Dedicated to Dr. B. Maurer on the occasion of his $77^{\text {th }}$ birthday

\begin{abstract}
This account corresponds to the presentation given by the main author on the occasion of the $2^{\text {nd }}$ Swiss Industrial Symposium in Basel (October 19 $\left.{ }^{\text {th }}, 2018\right)$. After a short historical introduction to methyl-jasmonate and methyl-epijasmonate, it essentially focuses on the reported more promising industrial approaches devoted to the synthesis of these naturally occurring odorants isolated from jasmine flowers. Some attempts to simplify these approaches, as well as independent unreported strategies are also presented. Several asymmetric methodologies are also discussed such as Xie hydrogenation, Corey-CBS reduction, enzymatic resolution, and 1,4-addition.
\end{abstract}

Keywords: Asymmetric · Halogenation · Hydrogenation· Jasmonate · Umpolung

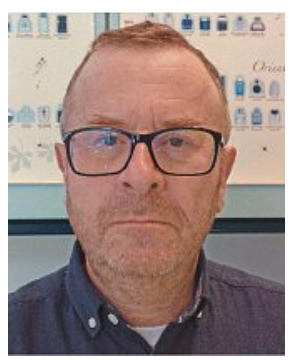

Christian Chapuis was born in Geneva in 1956. He received his $\mathrm{PhD}$ degree from the University of Geneva in 1984. Under the supervision of the late Prof. W. Oppolzer, he discovered the camphor sultam amongst other chiral auxiliaries for asymmetric Diels-Alder reactions. In 1985 he conducted his postdoctoral fellowship at UC Berkeley with Prof. P. A. Bartlett, before pursuing his independent work at the Institute of Organic Chemistry of the Polish Academy of Sciences in Warsaw, in collaboration with Prof. J. Jurczak. In 1987 he started his research on new perfume ingredients and processes at Firmenich SA, and in parallel was appointed lecturer at the University of Geneva in 1999. He has been a member of the Alfred Werner Fund Allocation Committee since 2009, and was member of the advisory board of Helvetica Chimica Acta from 2001 to 2016. He is currently a principal scientist, recently deprived of his laboratory's team, his current task consists of analysing competitors' patents.

\section{Introduction}

Jasminum grandiflorum L, growing all around the Mediterranean sea, is a variety of Jasminum officinale L. ubiquitous in the lower valleys of the Himalayas. One ton of flowers, cultivated on $c a .2000 \mathrm{~m}^{2}$, affords after extraction with ethanol and evaporation, $\mathrm{ca} .2 .3 \mathrm{~kg}$ of jasmine concrete. This natural extract, more expensive than gold, was used in practically every perfume at the beginning of the $20^{\text {th }}$ century. The annual production, limited to $c a$. 6 tons per year at that time, encouraged Ruzicka, the head of research at Firmenich, to analyze in depth the composition of this floral extract, as early as $1925 .{ }^{[1]}$ Although he succeeded in determining more than $87 \%$ of its composition, the structure of the active principle, responsible for the wonderful radiance and

${ }^{*}$ Correspondence: Dr. C. Chapuis

E-mail: christian.chapuis@firmenich.com

Corporate R\&D Division, Firmenich SA, Synthesis Department, POBox 239,

$\mathrm{CH}-1211$ Geneva 8 deep floral character, remained a mystery. It was only in 1957 , that Demole, who was sent to Paris by Roger Firmenich for his $\mathrm{PhD}$ thesis, discovered the hidden active principle, representing less than $0.8 \%$ of the absolute mixture, and could attribute its structure on the basis of IR, UV and MS analyses. Its identity and $(Z)$-stereochemistry was soon confirmed by a non-regio selective synthesis, as well as by chemical degradation and perhydrogenation, which led to the serendipitous discovery of the saturated analogue Hedione ${ }^{\circledR}$ (Scheme 1).

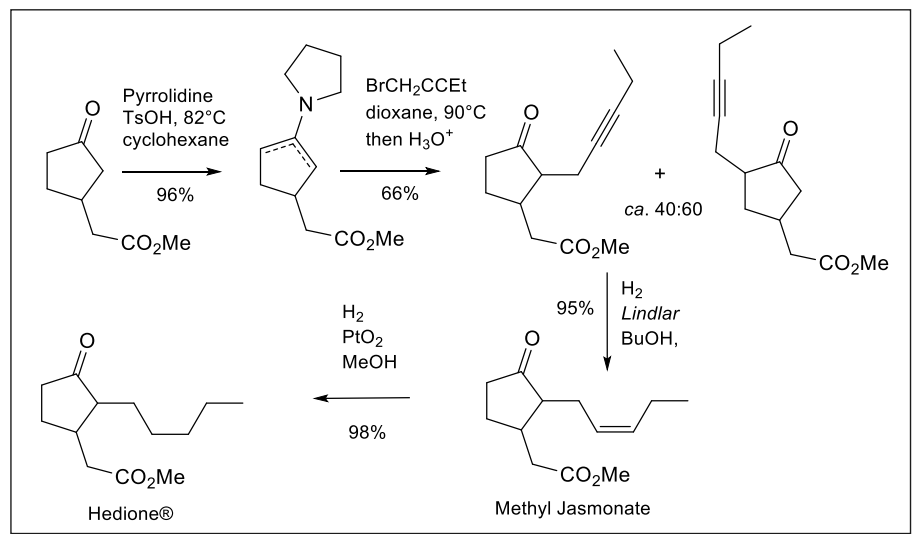

Scheme. 1. The first non-regioselective synthesis of Me-jasmonate and Hedione $^{\circledR}$ by Demole and Stoll. ${ }^{[3]}$

These discoveries were patented in 1960,,2] and published in $1962,{ }^{[3]}$ and allowed the famous perfumer Roudnitska to incorporate this simpler Hedione ${ }^{\circledR}$ ingredient in 'Eau Sauvage' (C. Dior, 1966), a perfume that still exists on the market today. Methyl jasmonate occurs in Tunisian Rosmarinus officinalis L., ${ }^{[4]}$ and has been also found in several citrus fruits, ${ }^{[5]}$ flowers, ${ }^{[6]}$ or tea flavors. ${ }^{[7]}$ This unsaturated molecule possesses a range of biological activities, ${ }^{[8]}$ such as plant defense, or growth regulation, ${ }^{[9]}$ as well as signal transmission between either plants, ${ }^{[10]}$ and/or insects. ${ }^{[11]}$ Its natural biosynthesis, starting from $\alpha$-linolenic fatty acid, was described by Vick and Zimmerman (Scheme 2) ${ }^{[12]}$ and 
the cis-stereoisomer was claimed to be the biologically active species. ${ }^{[13]}$ The trans-form, resulting from a thermodynamic epimerization during the methyl jasmonate extraction/purification, corresponds to an isolation artefact.

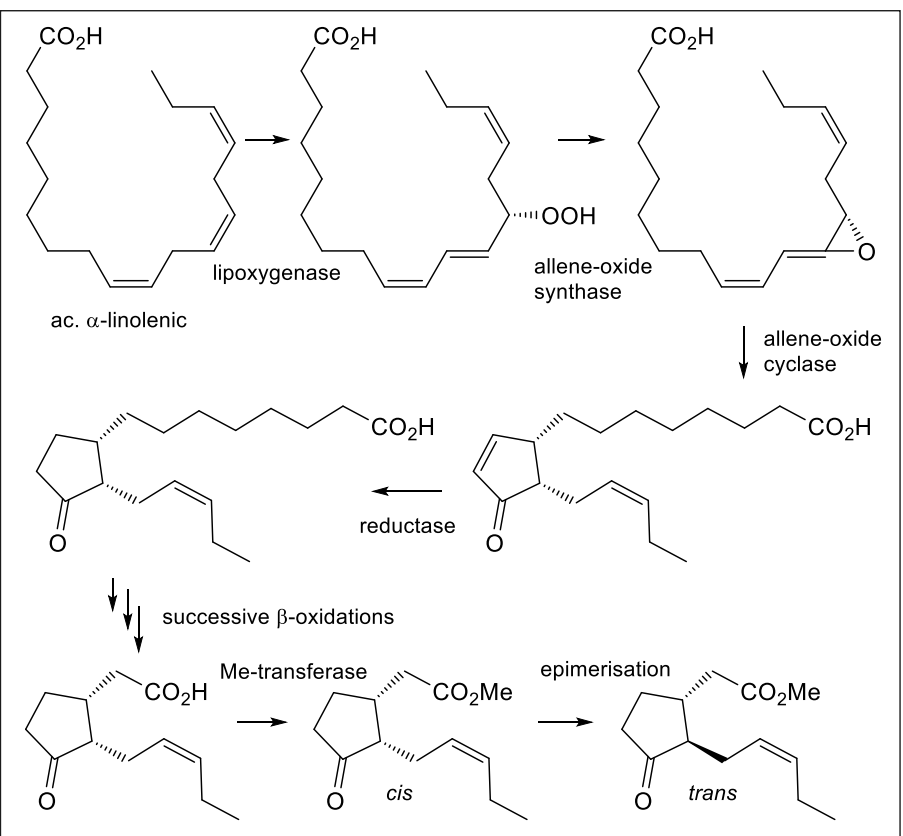

Scheme. 2. Biosynthesis according to Vick and Zimmerman. ${ }^{[12]}$

It is also the (+)-(Z)-cis-stereoisomer, named methyl epijasmonate, which is olfactively responsible for the desired powerful and radiant scent (Fig. 1). ${ }^{[13]}$ In a non-stabilized $\mathrm{pH}$ perfume composition the epijasmonate thus epimerizes, and only $3-5 \%$ of the diastereoisomeric mixture is responsible for the scent.

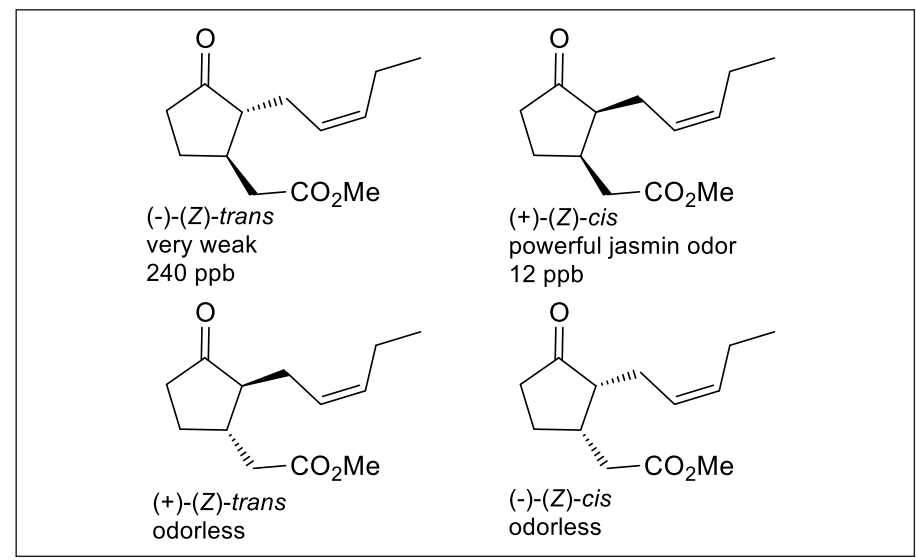

Fig. 1. Olfactive properties of individual stereoisomers. ${ }^{[13]}$

\section{Industrial Approaches}

Numerous academic syntheses were reported and have been reviewed throughout the last sixty years. ${ }^{[14]}$ We present and discuss here only the most promising industrial approaches, as well as some of our attempts towards their modification or simplification.

The first synthesis, published in 1971, by both our former consultant Büchi and colleague Egger, ${ }^{[15]}$ started from 1,3-cyclohexadione (Scheme 3). After sequential alkylation and halogenation of the activated position, treatment under basic conditions and subsequent heating allowed the liberation of carbon monoxide, to afford the strategic 2-(pent-2-yn-1-yl)cyclopent-2-en-1-one. At this stage, several options were possible, including the 1,4-addi- tion of dimethyl malonate (DMM), followed by decarbomethoxylation and semi-hydrogenation, ${ }^{[3 c, 15]}$ or vice versa. Alternatively the sequence may be inverted by first performing the semi-hydrogenation, ${ }^{[15]}$ followed by Michael addition, and the final decarbomethoxylation, resulting in production of methyl jasmonate. ${ }^{[16 a, b]}$ A less efficient alternative consisted of performing the semi-hydrogenation directly after the initial alkylation, prior to the halogenation and $\mathrm{CO}$ extrusion. Partial hydrogenation of the chlorinated intermediate has not been reported to date.

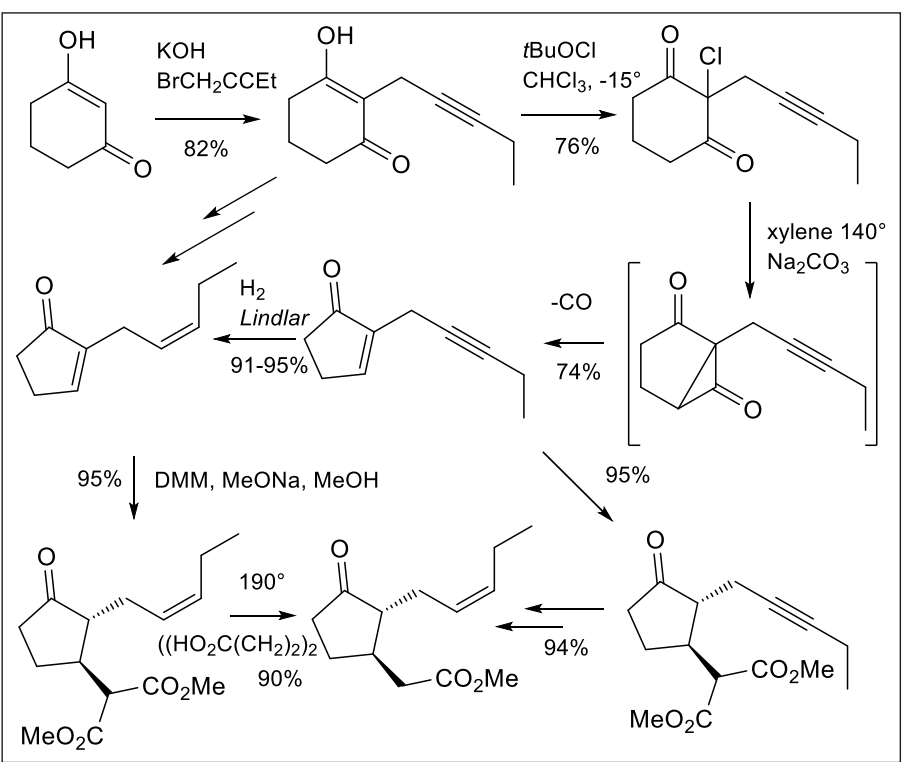

Scheme. 3. The Büchi and Egger synthesis starting from 1,3-cyclohexadione. ${ }^{[15]}$

The second approach by Johnson and Paul, at Dow Chemical, was patented in 1977 (Scheme 4). ${ }^{[17]}$ It started from a symmetrical bis-keto-ester, readily accessible from either methyl acetoacetate, ${ }^{[18]}$ or succinoyl chloride, ${ }^{[19]}$ or 6-methoxy-4,6-dioxohexanoic acid. ${ }^{[20 a]}$ An intramolecular Knoevenagel condensation under basic conditions, prior to simple hydrogenation and alkylation with 1-bromo-2-pentyne, followed by full saponification gave, after concomitant thermal decarboxylation, a keto acid. This strategy necessitates a re-esterification, prior to semi-hydrogenation. This sequence may eventually be shortened by either a single transformation, ${ }^{[21]}$ or a one-pot acidic hydrolysis/decarboxylation/ re-esterification in methanol,[22] or more simply via a Krapcho decarbomethoxylation. ${ }^{[23]}$ Based on the chiral pool, an asymmetric synthesis was then devised by Weinges et al.[21] Starting from (-)-catalpol, the optically pure intermediate saturated ketodiester was used to similarly generate (-)-methyl jasmonate in sixteen steps and $7 \%$ overall yield. Alternatively this central key intermediate could also be obtained either from $(S)-(-)$-malic acid[20c-e] or via a camphanate resolution, ${ }^{[22]}$ or by involving an inductive camphor derived auxiliary, ${ }^{[20 f]}$ or more simply by asymmetric hydrogenation of its prochiral precursor, using the commercially available $(R)$-Ir-spiroPAP catalyst. ${ }^{[20 a, b]}$ Here again, after identical alkylations, the two last steps may also eventually be inverted by culminating with the Krapcho decarbomethoxylation as reported by Torii et al. ${ }^{[23]}$

One year later, the linear approach of Dubs and Stüssi at Givaudan makes use of (3Z)-hexenyl Grignard reagent, generated from the corresponding bromide (Scheme 5). ${ }^{[16 b]}$ Its addition to acrolein afforded an allylic alcohol, which was re-oxidized prior to the Michael addition of nitromethane anion. The subsequent Nef reaction generates a keto-aldehyde ready for intramolecular aldol condensation. ${ }^{[24]}$ In order to work at the correct level of oxidation, we attempted the (3Z)-hexenyl Grignard addition of the 


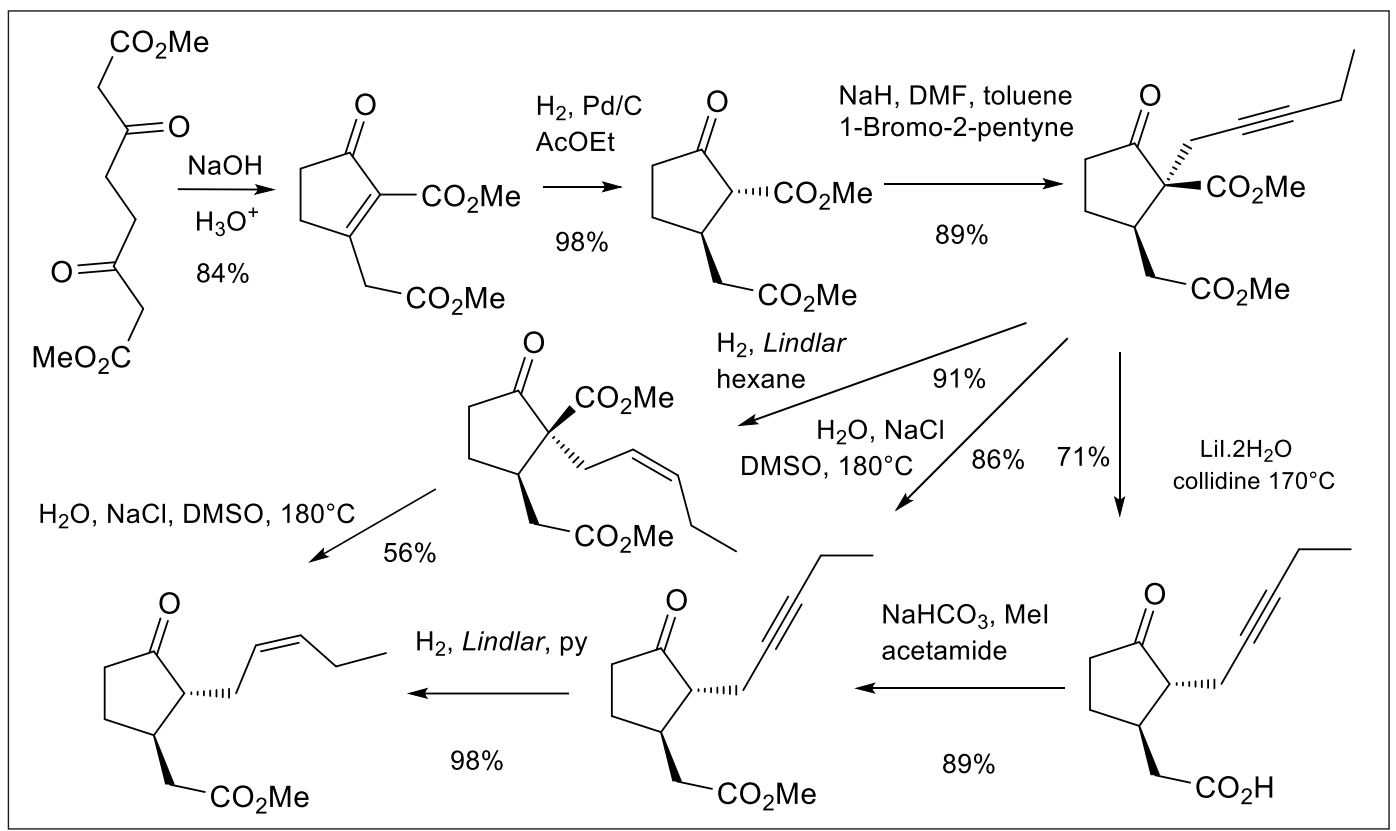

Scheme 4. The Johnson and Paul synthesis, suitable for an industrial asymmetric version. ${ }^{[17,20,21,23]}$

corresponding chloride under Negishi transmetallation conditions to acryloyl chloride, ${ }^{[25]}$ and could isolate directly the intermediate enone, albeit in only $34 \%$ yield. We were no more successful when this addition was performed on 3-chloro propanoyl chloride in the presence of $\mathrm{MnCl}_{4} \mathrm{Li}^{[26]}$ with subsequent $\beta$-elimination. Alternatively, in 2012 this Grignard addition was performed on the commercially available 4-chlorobutyronitrile in 52\% yield, but the envisaged Kornblum oxidation allowed the isolation of the intermediate keto-alcohol, ${ }^{[27]}$ already reported for a PCC oxidation towards the expected keto-aldehyde. ${ }^{[28]}$ Furthermore, the direct $\mathrm{S}_{\mathrm{N}} 2$ displacement of the primary chloride by DMAP- $N$-oxide, followed by subsequent in situ DBU elimination of DMAP, [29] afforded directly the desired product of oxidation, albeit in only $22 \%$ yield, as the main isolated product was the (3Z)-hexenylcyclopropyl ketone, exhibiting a green, freshly cut grass scent.
The same year, Naef and Decorzant at Firmenich proposed an elegant approach based on the bromination of piperylene, followed by double alkylation of the readily available cyclopentanone (Scheme 6). ${ }^{[30]}$ Alternatively, we also similarly performed this alkylation, using the crude bis-mesylate, obtained from pent2-ene-1,4-diol, readily available from either but-2-yn-1,4-diol, [31] or piperylene, ${ }^{[32]}$ or cyclopenta-1,3-diene, as reported by SchulteElte et al. ${ }^{[33]}$ The resulting spirocyclopropyl intermediate was submitted to thermolysis, thus both equilibrating the diastereoisomeric mixture, and stereoselectively generating the rearrangement giving the $(Z)$-double bond. The last steps were as previously reported. In order to avoid this alkylation, we also envisaged an aldol condensation between cyclopentanone and crotonaldehyde, with in situ subsequent Corey-Chaykovsky regioselective cyclopropanation, if both base and solvent were carefully chosen to

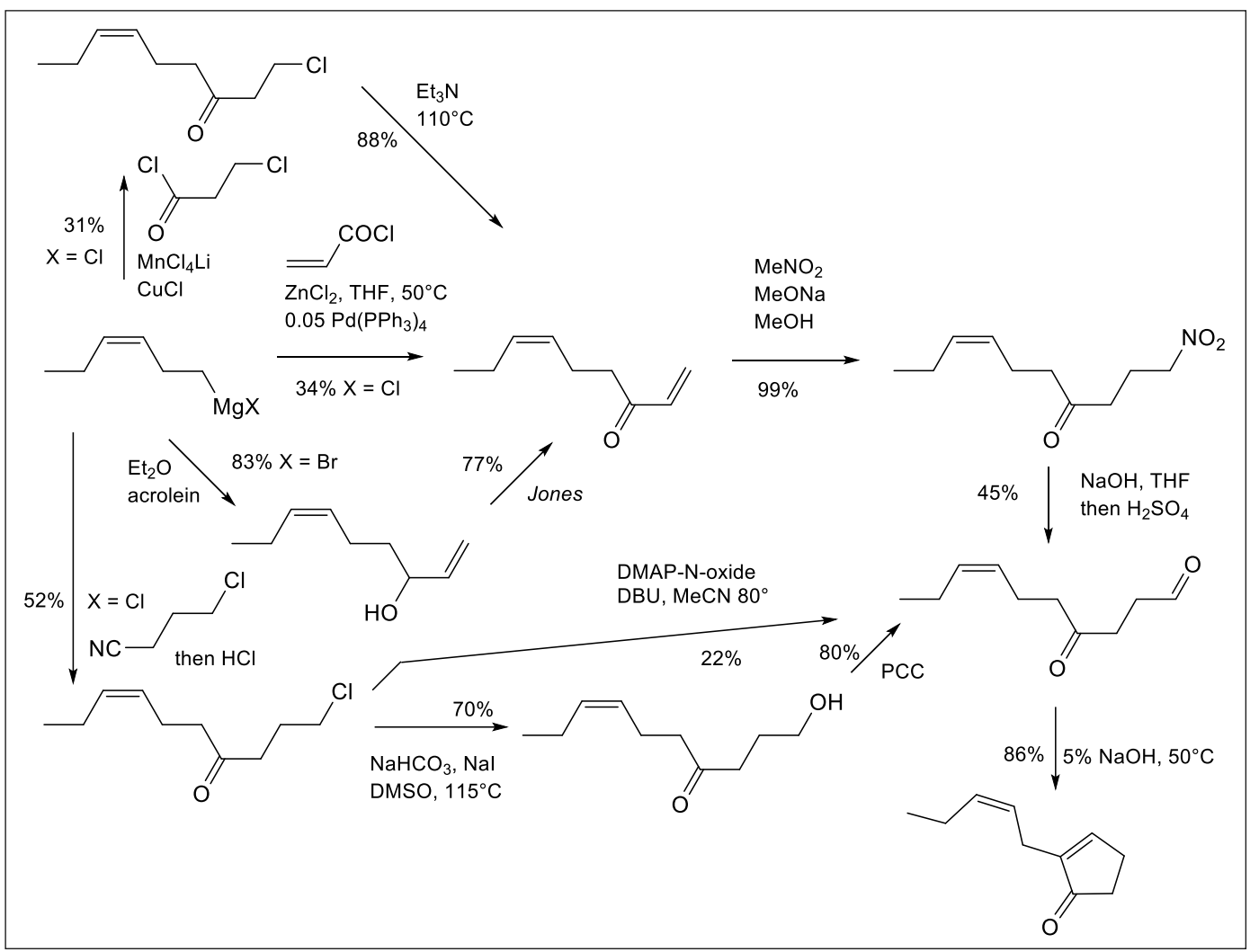

Scheme 5. The Dubs and Stüssi synthesis based on Grignard addition to acrolein, ${ }^{[16 b]}$ as well as our attempted shorter modifications. 
allow this one-pot cascade transformation. ${ }^{[34]}$ The regioselectivity results from the fact that the $\alpha, \beta$-unsaturation is fully planar and conjugated with the carbonyl, in contrast to the $\gamma, \delta$-double bond, which is slightly skew to the $\pi$-system, due to the steric interaction between the side-chain $\mathrm{C}(\gamma)-\mathrm{H}$ and the cyclic $\mathrm{CH}_{2}(\beta)$. Furthermore, for the same reason, the $(E)$-disubstituted double bond is less strained and reactive than the trisubstituted one, possessing a (Z)-disposition for two of its substituents. [14d]). Alternatively, a racemic mixture of the latter may also be enzymatically resolved to generate the desired enantiomer, while the undesired one may be recycled by acidic racemization. ${ }^{[36,37]}$ The appropriate enantiomer is esterified to afford either the corresponding acetate, or the monomethyl malonate. In the first case, in analogy to Helmchen's methodology, displacement of the $\pi$-allyl Pd complex with the anion of dimethyl malonate affords an intermediate cyclopentene derivative. Alternatively, either a

\section{Scheme 6. The Naef and} Decorzant synthesis, based on a double alkylation followed by a stereoselective thermal sigmatropic rearrangement, ${ }^{[30]}$ as well as our aldol and regio-selective Corey-Chaykovsky modified version. ${ }^{[34]}$

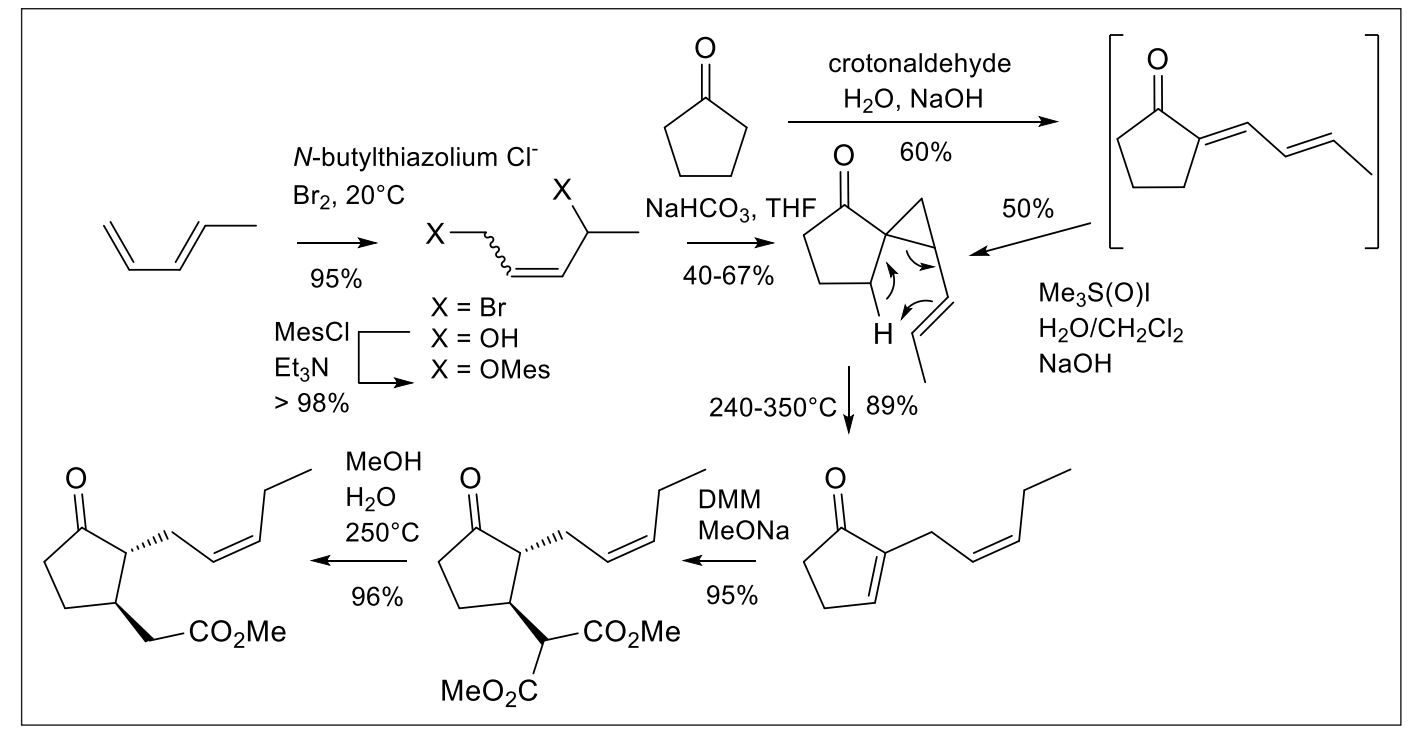

In 1987 Tsuji et al., in collaboration with Nippon Zeon, published the intramolecular Dieckmann condensation of diallyl adipate with concomitant alkylation of the activated position (Scheme 7). ${ }^{[35]}$ The key step is based on an intramolecular decarboxylative dehydrogenation of an allyl ester, catalyzed by $\mathrm{Pd}(\mathrm{OAc})_{2}$, which efficiently generates the known 2-pent-2-ynylcyclopent-2-enone, ready for partial hydrogenation. It is noteworthy that the analogous sequence using (2Z)-1-chloro-pent-2-ene is less performant during the dehydrogenation step.

At the start of the millennium, Fehr et al. at Firmenich proposed the unique stereo and enantio-selective industrial approach, based on the prochiral (Z)-2-(pent-2-en-1-yl)cyclopent-2-en-1-one, which was reduced according to Corey's CBS methodology to the corresponding allylic alcohol (Scheme 8, for more tedious approaches towards (+)-methyl epijasmonate, see references in

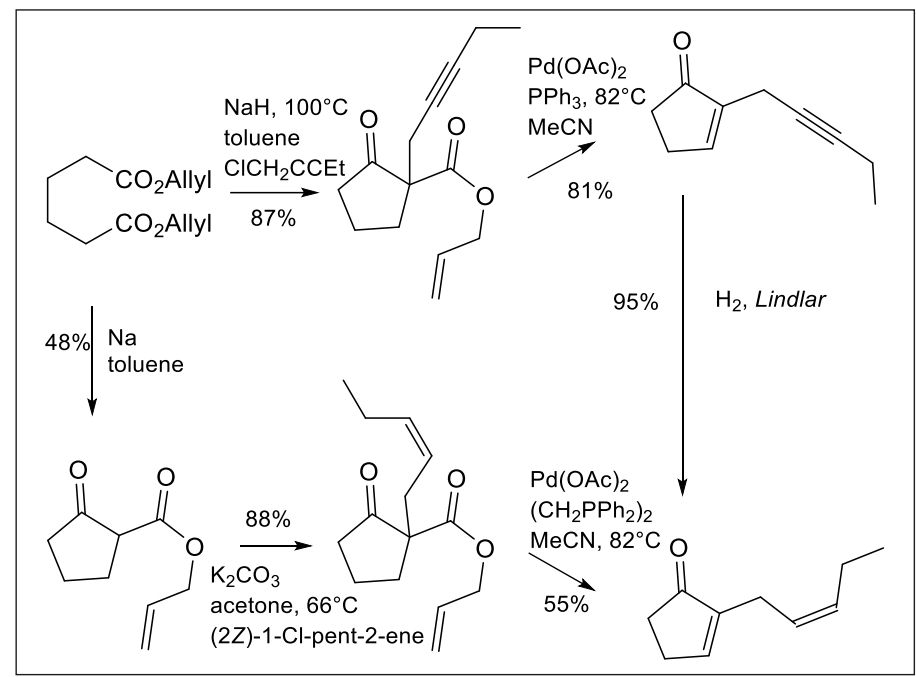

Scheme 7. The Tsuji et al. industrial synthesis, based on a Pd-catalyzed decarboxylative dehydrogenation. ${ }^{[35]}$ simple Carroll, or a TMS Claisen-Ireland rearrangement from the monomethyl malonate, generates a similar intermediate. ${ }^{[37]}$ In both cases, respective decarboxylation allows the generation of the methylacetate side chain, useful in stereoselectively directing the subsequent epoxidation. The ultimate suprafacial migration of the $\mathrm{H}$-atom, during the epoxide rearrangement, installs the desired cis-configuration of both side chains of (+)-methyl epijasmonate.

In 2005, we reported a particularly efficient cascade BaylisHillman/Claisen-Johnson rearrangement, between the commercially available cyclopent-2-enone, readily oxidized from cyclopentanone, ${ }^{[38]}$ and glyoxaldimethylacetal, with subsequent acidic thermal treatment with trimethylorthoacetate (Scheme 9). ${ }^{[39]}$ The resulting exo-cyclic unsaturation could be hydrogenated to produce mainly the cis-stereoisomer. Unfortunately the side chain later epimerized into the trans-disposition during the acidic acetal deprotection.

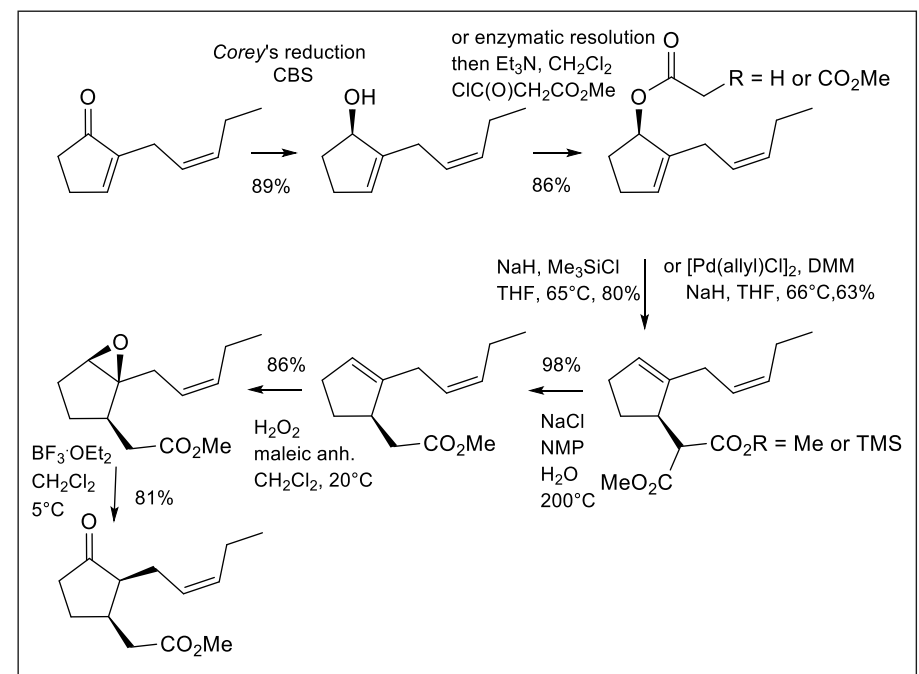

Scheme 8. Fehr et al. industrial stereo- and enantio-selective synthesis of the active (+)-(Z)-Me-epijasmonate. ${ }^{[36,37]}$ 
Finally a $(Z)$-selective Wittig reaction finalizes the synthesis.[40] Alternatively, the exo-cyclic double bond could be isomerized into the endo-cyclic tetrasubstituted thermodynamically more stable position, and this prochiral acetal was either hydrogenated to the pure cis-acetal, or deprotected, prior to another $(Z)$-selective Wittig reaction. We unfortunately found, at that time, that 1,4-hydride reduction using $\mathrm{NaBH}_{3} \mathrm{CN}$ was inefficient to generate the desired methyl jasmonate, even under refluxing $\mathrm{MeOH}$ conditions. ${ }^{[41]}$

One year later, we published the shortest approach ever devised (Scheme 10). ${ }^{[42]}$ Again starting from the commercially available cyclopent-2-enone, we performed an efficient DielsAlder reaction with chloroprene ( $75 \%$ yield), a readily available reactant used in the plastic industry. Indeed this diene is more stable than the non-commercial and unstable oxygenated butadiene analogues, as earlier reported in such similar cycloadditions (5-27\% isolated yield). ${ }^{[43]}$ Furthermore our cycloadduct is not prone to unsaturation isomerization under either cycloaddition or isolation conditions, although some epimerization is observed. chlorination/thermo-dehydrochlorination, but this process, abandoned twenty years ago by us and amazingly very recently patented by $\mathrm{IFF}^{[47 a]}$ (this patent is jeopardized by footnote 15 in ref. [14d], already disclosing the analyses of the key intermediate), has been replaced by a more industrial thermodynamic enolacetate formation, followed by peracetic epoxidation, with subsequent rearrangement under acidic work-up. ${ }^{[48]}$ We performed a consequent short-cut of this three-step sequence, by direct treatment of the malonate intermediate under Kochi's halogenation conditions, to afford, via a cascade single pot conversion, the sequential regio-selective $\alpha$-bromination of the ketone, followed by elimination and decarbomethoxylation, mediated by the resulting cuprous bromide in refluxing $\mathrm{MeOH} .{ }^{[49]} \mathrm{It}$ is noteworthy that both Hedione ${ }^{\circledR},{ }^{[49]}$ and even more indirectly its enol acetate, ${ }^{[47 b]}$ may also be subjected to these conditions. Similarly, endo-dehydro methyl jasmonate may be generated under the same conditions from methyl jasmonate (55\% yield, $67 \%$ yield based on recovered starting material, Scheme 9).

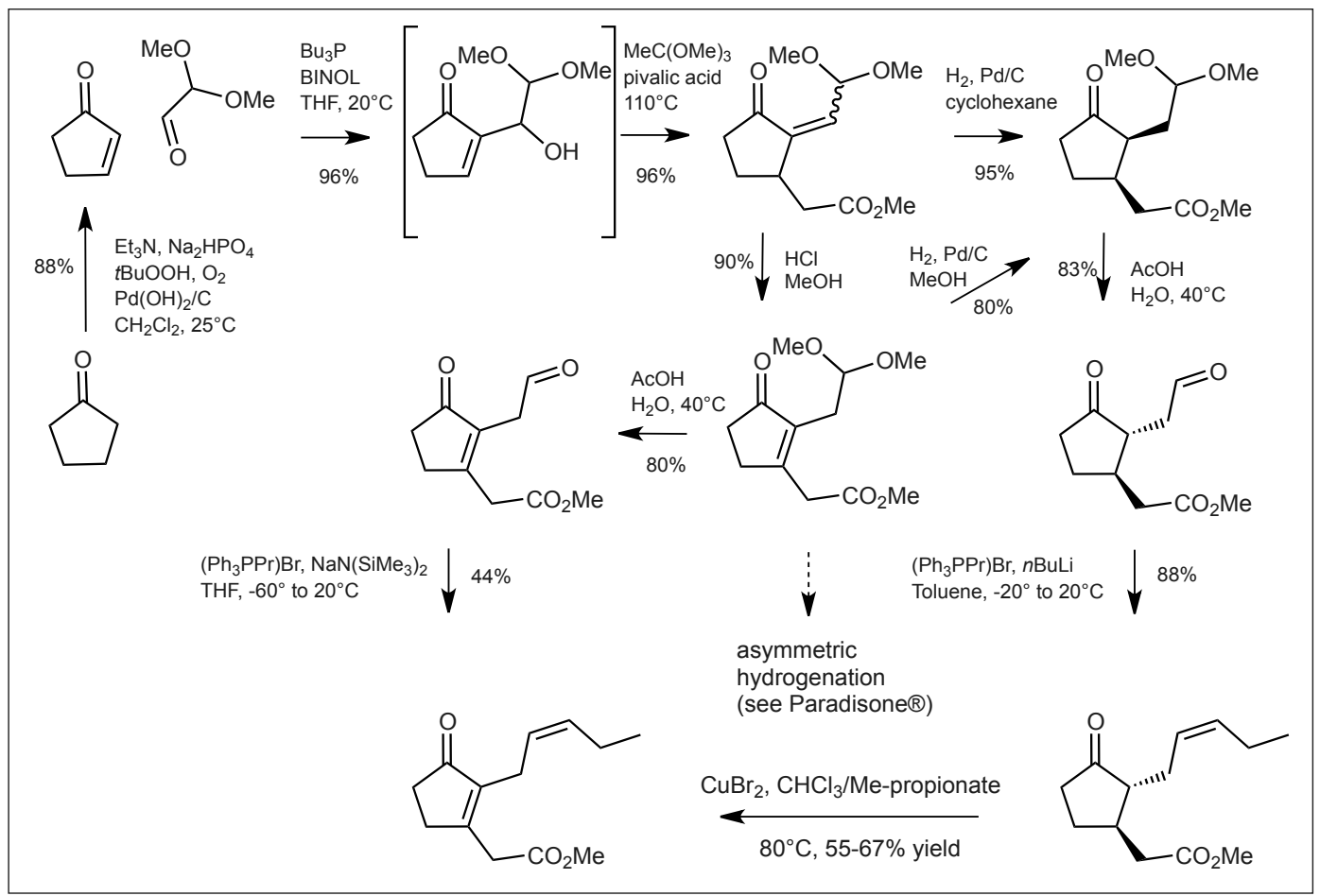

Scheme 9. The Chapuis et al. synthesis based on a cascade Baylis-Hillman/Claisen-Johnson rearrangement. ${ }^{[39]}$

This cycloadduct was then submitted to an ozonolysis with basic methanolysis during the work-up, thus directly generating both the required methyl-acetate and aldehyde side chains. The last step was performed as previously. The initial $\mathrm{cis} /$ trans ratio erodes all along the sequence from 55:45 to 20:80, and finally may be thermodynamically equilibrated to 7:93 under basic conditions.

In 2007, our colleagues Lem et al. modified this approach via the use of the final steps of the Hedione ${ }^{\circledR}$ synthesis, by performing the aldol condensation of glyoxaldimethylacetal with the cheaper cyclopentanone (Scheme 11). ${ }^{[44]}$ Here again, the exo-cyclic double bond was isomerized into the more stable endo-cyclic position. A 1,4-addition of dimethyl malonate, followed by Krapcho decarbomethoxylation gave, after deprotection, the known Wittig precursor. ${ }^{[39,40,42,44]}$

Indeed, Hedione ${ }^{\circledR}$ is similarly obtained by the dimethyl malonate 1,4-addition to 2-pentyl-cyclopent-2-enone, followed by decarbomethoxylation (Scheme 12). ${ }^{[14]}$ Its optically active version, named Paradisone ${ }^{\circledR}$, is the result of an asymmetric hydrogenation of what is known as DHH (diDeHydroHedione), ${ }^{[45]}$ spectacularly developed 'in house' by Rautenstrauch et al., with external collaborations. ${ }^{[46]} \mathrm{DHH}$ may be obtained directly from Hedione ${ }^{\circledR}$ by

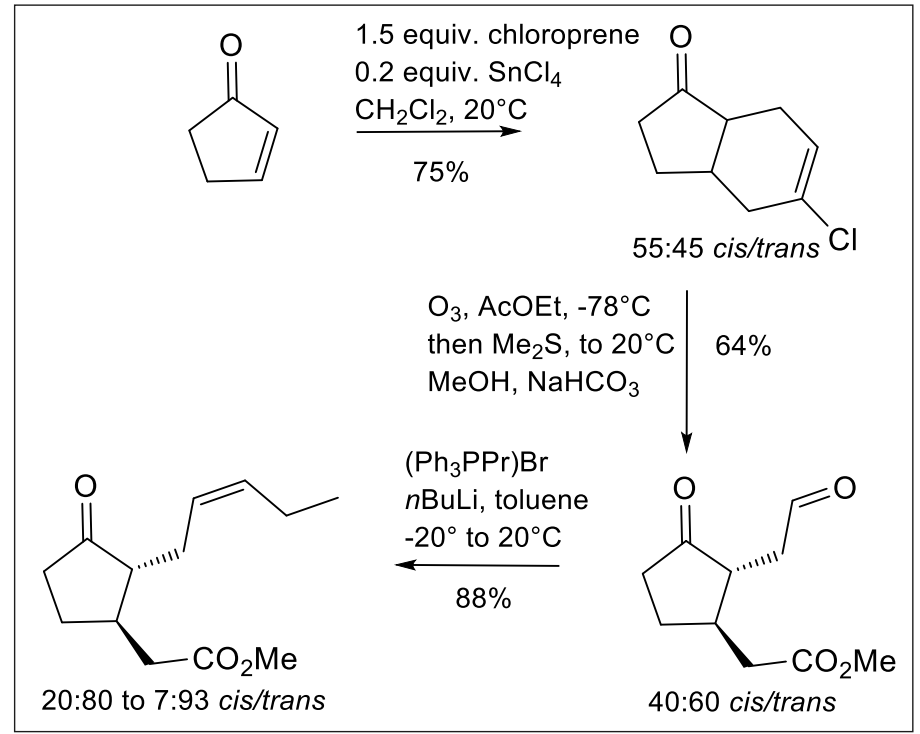

Scheme 10. The Chapuis et al. most consise synthesis based on an efficient Diels-Alder reaction with chloroprene. ${ }^{[42]}$ 
Scheme 11. The Lem et al. approach based on the Hedione ${ }^{\circledR}$ strategy, using cheap starting materials. ${ }^{[4]}$

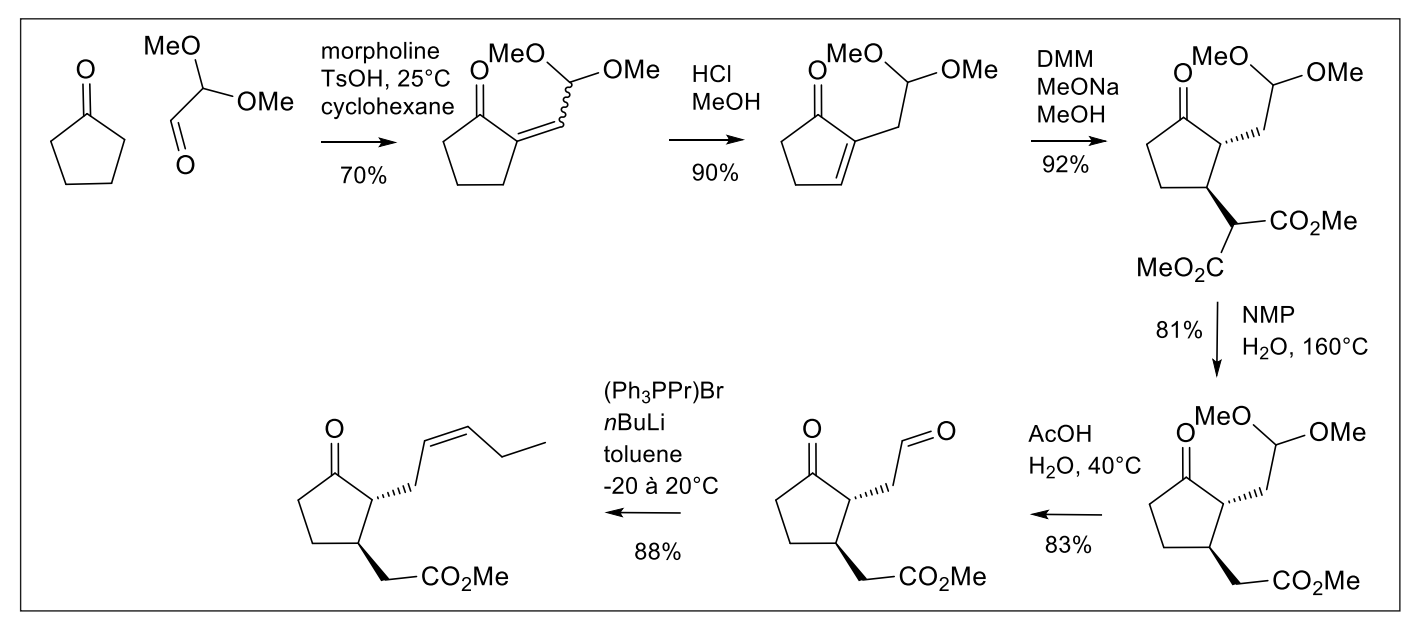

Scheme 12. The industrial syntheses of both $\mathrm{DHH}$ and Paradisone ${ }^{\circledR}$ according to Rautenstrauch et al. ${ }^{[45,46,48]}$ as well as our onepot cascade halogenation/ elimination/decarbomethoxylation approach. ${ }^{[49]}$

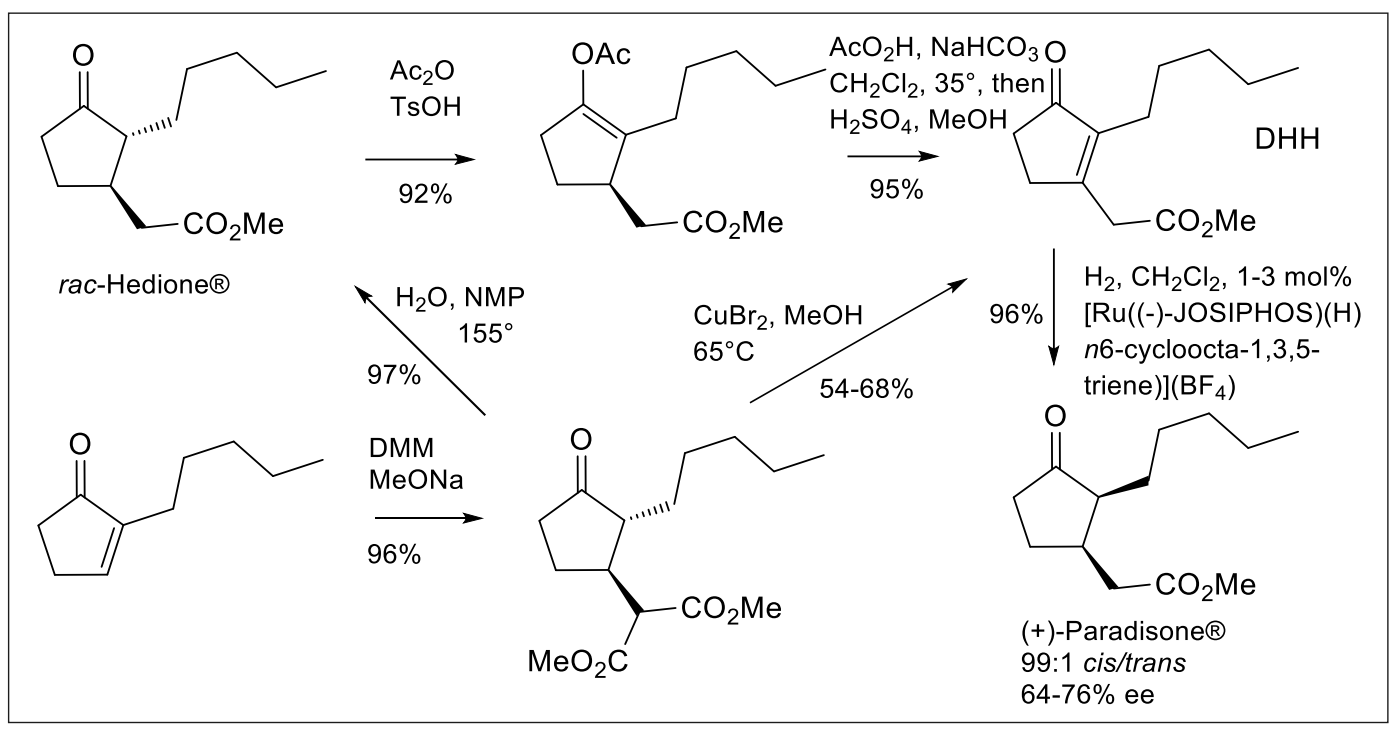

In 2016 we reported that these conditions, when applied to the usual ketoester with either a 2-pentynyl, or a (2Z)-pentenyl $\alpha$-side chain, afforded cleanly the $\alpha$-bromo intermediates, which now necessitate a stronger base, such as DBU, to promote their respective eliminations (Scheme 13). ${ }^{[34]}$ Similarly, the ester group, unable to generate the enol form with the ketone, needs to be hydrolyzed with $\mathrm{LiOH}$ in $\mathrm{THF} / \mathrm{H}_{2} \mathrm{O}$, prior to decarboxylation. Both the intermediate enones may be isomerized, via their enolates, into their respective thermodynamically more stable regioisomers, ${ }^{[14 \mathrm{~d}, 16 \mathrm{~b}, \mathrm{c}, 50]}$ while the semi-hydrogenation of the triple bond is similarly efficient on all three possible intermediates.

The conditions reported by French chemists, using 10 mol\% of $N$-(antracen-9-ylmethyl)quinidinium chloride, for the catalytic asymmetric 1,4-additions of dimethyl malonate for a synthesis of optically active trans-Hedione ${ }^{\circledR}$, were used as a starting point. ${ }^{[51 \mathrm{a}, \mathrm{b}]}$ Lem et al., but working at $0{ }^{\circ} \mathrm{C}$ in order to increase the reaction kinetic, obtained $58 \%$ ee in $78 \%$ yield from their prochiral acetal after $18 \mathrm{~h}$ (Scheme 14). ${ }^{[44]}$ Under the same conditions, but applied to cyclopent-2-enone bearing the (2Z)-side chain, we reached $75 \%$ ee in $97 \%$ yield. The enantioselectivity strongly depends on the $\alpha$-side chain, as the more linear pent-2-ynyl analogue dropped to only $48 \%$ ee and $84 \%$ yield under identical conditions. ${ }^{[34]}$ More recently, another example of quinine-catalyzed Michael addition to methyl 5-oxocyclopent-1-en-1-carboxylate prompted us to test this substrate. ${ }^{[51 c]}$ Unfortunately, under conditions developed by Plaquevent et al., the 1,4-addition was inefficient due to the instability of the starting material. The opposite sense of induction may be
Scheme 13. The Chapuis et al. approach via sequential halogenation, elimination, saponification, decarboxylation and isomerization towards a Me-jasmonate key precursor. ${ }^{[34]}$

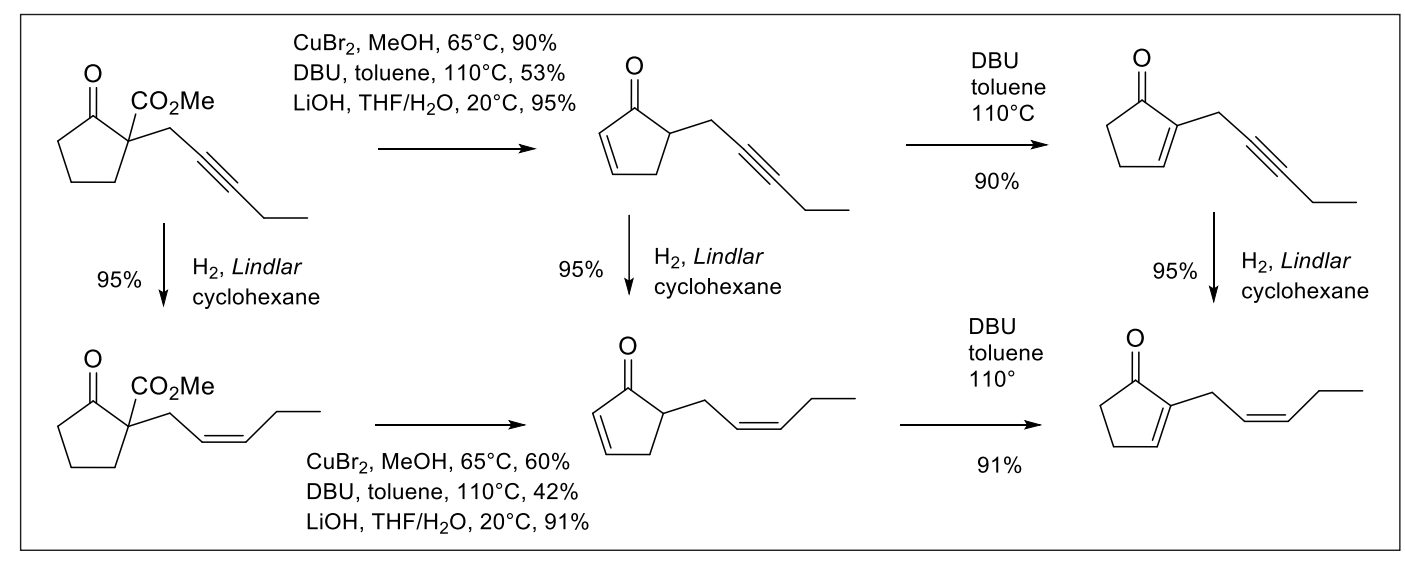


obtained by using $N$-(anthracen-9-ylmethyl)quininium chloride as pseudoenantiomeric catalyst. In the case of 2-pentylcyclopent-2-en1 -one, the catalyst may eventually be supported, ${ }^{[51 \mathrm{~b}]}$ or replaced by $20 \mathrm{~mol} \%$ of a $\mathrm{Li}$ salt of a $(R)-\beta$-amino acid (DMSO, $\mathrm{CH}_{2} \mathrm{Cl}_{2}, 10$ mol.-equiv. DMM, $20{ }^{\circ} \mathrm{C}, 48 \mathrm{~h}$, two chromatographies to isolate the cis-dimethyl 2-((1S,2S)-3-oxo-2-pentylcyclopentyl)malonate in 24\% yield. [51d] Interestingly, according to Zhang and Yang, a final Krapcho decarbomethoxylation (DMSO, $\mathrm{H}_{2} \mathrm{O}, 190{ }^{\circ} \mathrm{C}, 10 \mathrm{~h}, 60 \%$ yield after chromatography) afforded the (+)-cis-dihydrojasmonate (Paradisone $^{\circledR},[\alpha]_{\mathrm{D}}{ }^{20}=+75, \mathrm{c}=1.2, \mathrm{CH}_{2} \mathrm{Cl}_{2}$ ) with $\mathrm{ca}$. 85-90\% ee based on chiroptical properties $\left([\alpha]_{\mathrm{D}}{ }^{20}=+83.5 \mathrm{c}=1.19, \mathrm{CHCl}_{3}\right.$, $94 \%$ ee; ${ }^{[45]}[\alpha]_{\mathrm{D}}{ }^{20}=-88.4, \mathrm{c}=1.24, \mathrm{CHCl}_{3}$ for the enantiomer, $96 \%$ ee: $\left.{ }^{[45]}[\alpha]_{\mathrm{D}}{ }^{20}=+83.4, \mathrm{c}=0.58, \mathrm{CHCl}_{3}\right) .^{[5 \mathrm{e}]}$

In 2017 Mahaim et al. at Mane reported another (3Z)hexenylMgCl Grignard addition, but now to a Weinreb amide, obtained in four steps from 2-chloro acetyl chloride (Scheme 15). ${ }^{[52]}$ The sequence comprised of the addition of methoxymethylamine, then preparation of a Wittig reagent via an Arbusov reaction with triethylphosphite, and addition to glyoxaldimethylacetal in pres- ence of $\mathrm{K}_{2} \mathrm{CO}_{3}$. A hydrogenation concludes the preparation of the desired Weinreb substrate. After the Grignard addition (70\% yield), a further acidic hydrolysis is necessary to deprotect the acetal, in order to perform the intramolecular aldol condensation in $86 \%$ yield. ${ }^{[52]}$ We simplified this particularly lengthy approach by performing the same Grignard addition on the commercially available 4,4-dimethoxybutanenitrile, readily obtained by hydroformylation of acrylonitrile in $\mathrm{MeOH}$, according to an old $\mathrm{Du}$ Pont de Nemours patent. ${ }^{[53]}$ This single-pot reaction, culminating with an acidic work-up, enabling the concomitant hydrolysis of both the intermediate imine and the acetal, affords the desired keto-aldehyde in $48 \%$ yield, thus more efficiently than the $40 \%$ overall yield resulting from the corresponding six-step sequence.

In order to avoid a relatively expensive Grignard reaction, we also studied two additional approaches. The first one was in analogy to the methodology developed by Kulinkovich et al., ${ }^{[54]}$ and involved a Friedel-Craft reaction between (3Z)-hexenoyl chloride and allyl chloride, mediated by $\mathrm{AlCl}_{3}$, to afford after basic treatment with an excess of $\mathrm{MeONa}$, directly the previous keto-

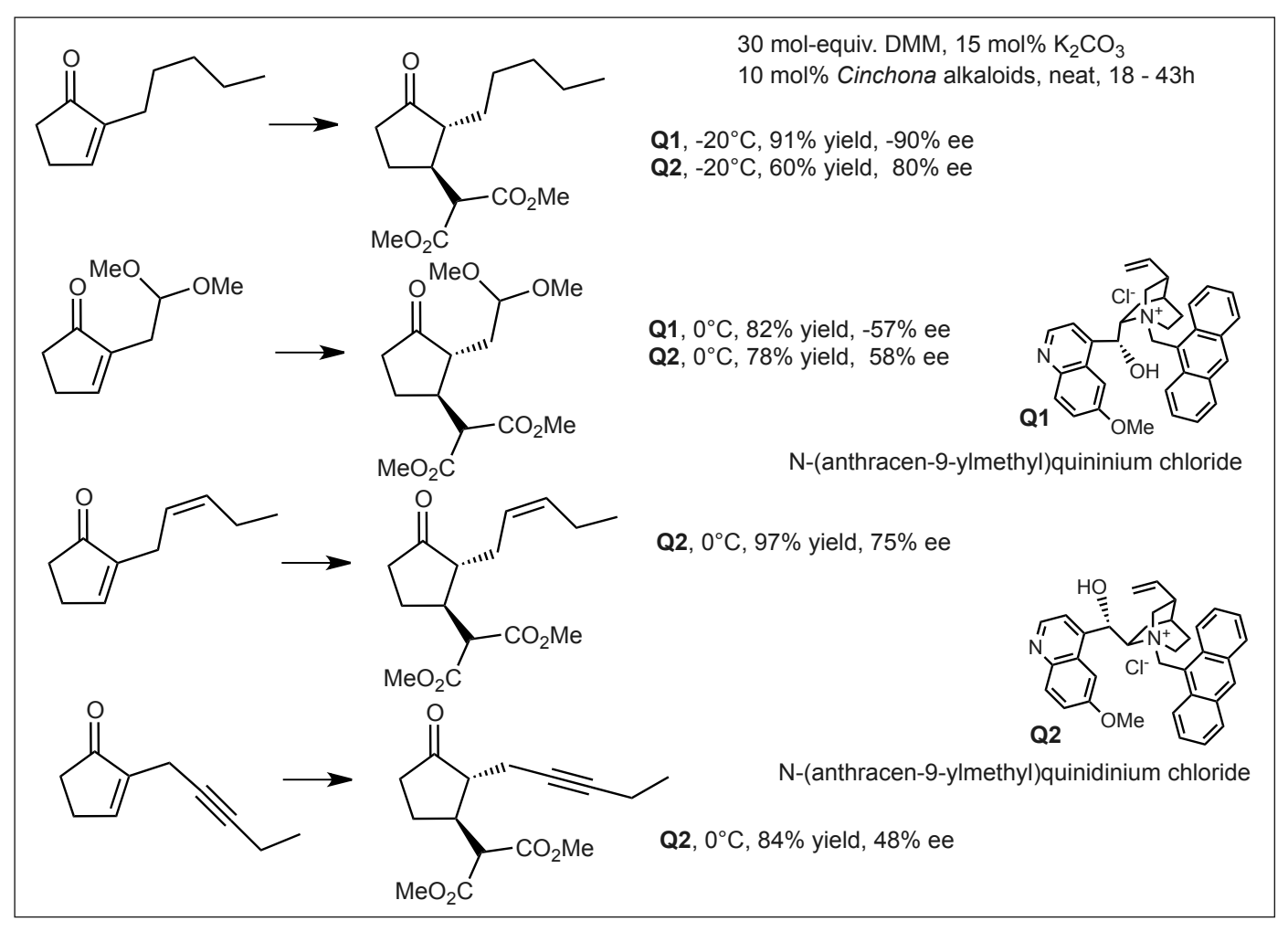

Scheme 14. The Plaquevent et al. asymmetric Michael addition of DMM, ${ }^{[51 a]}$ applied to (-)-(Z)Me-jasmonate precursors. ${ }^{[34,44]}$

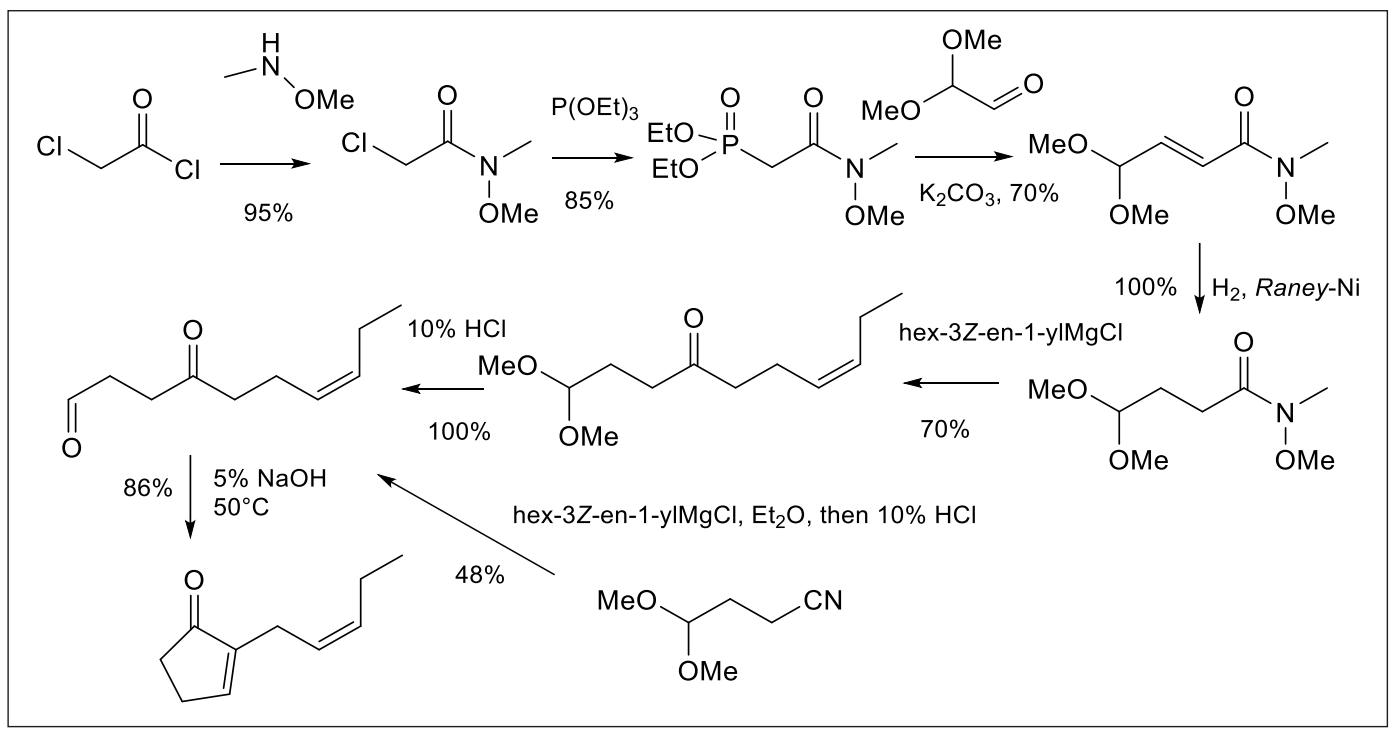

Scheme 15. The Mahaim et al. strategy, based on a Grignard reaction to a Weinreb amide, ${ }^{[52]}$ as well as our one-pot similar addition/hydrolysis, using a commercially available industrial starting material. 
acetal intermediate in $36 \%$ yield (Scheme 16). According to the mechanism suggested by the Russian authors, the first adduct is deprotonated by one equivalent of base to form a chlorocyclopropyl ketone. Either a direct $\mathrm{S}_{\mathrm{N}} 2$, or a $\beta$-elimination with a second equivalent of base, followed in the latter case by a Michael addition, affords the methoxycyclopropylketone, which is then attacked by a supplementary equivalent of $\mathrm{MeONa}$, thus regenerating the linear enolate.

Our second 'Umpolung' approach was based on a Stetter reaction (Scheme 17). ${ }^{[55]}$ The commercially available hept-(4Z)-enal is treated in refluxing 1,4-dioxane with isobutyl acrylate in the presence of $\mathrm{Et}_{3} \mathrm{~N}$ and $20 \mathrm{~mol} \%$ of catalyst to afford the desired keto-ester in $54 \%$ yield. The same reaction performed with only $5 \mathrm{~mol} \%$ of catalyst in a recyclable ionic solvent with either ethyl acrylate or acrylonitrile, is less satisfactory, but the latter reaction could also be conducted under neat conditions. ${ }^{[56]}$ In that case the keto-nitrile was subjected to an acidic ethanolysis to afford the same keto-ester. ${ }^{[16 b]}$ A complete $\mathrm{LiAlH}_{4}$ reduction, followed by a Swern re-oxidation afforded the desired keto-aldehyde.
This Stetter reaction with either ethyl acrylate or acrylonitrile could also be performed in refluxing $\mathrm{EtOH}$, then quenching with triethylorthoformate to afford the corresponding ketals (Scheme 18). ${ }^{[57]}$ This strategy allowed the final reduction with DIBAL with an acidic work-up, so that the intermediate ketal is deprotected in situ. Reduction via the nitrile pathway is nevertheless preferred, in terms of both yield and a more industrial reaction temperature. The moderate chemical yields resulting from these Stetter reactions originated from the chromatographic purification, necessary to separate the desired adducts from the acyloin side-product.

Considering alternative $\mathrm{C} 4$ synthons, we eventually alkylated furan with either (3Z)-hexenyl bromide (BuLi/THF at $-20{ }^{\circ} \mathrm{C}$, $92 \%$ yield, ${ }^{[58 \mathrm{a}]}$ for an alternative Wittig approach on furfural, see ref. [59]), or with the less efficient hex-3-ynyl bromide (25\% yield, as a consequence of an easier halide elimination side reaction). [58b] In the former case, subsequent oxidation of the furan moiety is more limited due to the reactivity of the double bond towards either $m$ CPBA or NBS for example. ${ }^{[60,61]}$ We were not interested in using either $\mathrm{Br}_{2},{ }^{[62]}$ or anodic oxidation, ${ }^{[63]}$ or photolysis, ${ }^{[64]}$ or
Scheme 16. Our one-pot synthesis, based on the Kulinkovich et al. Friedel-Craft/methylate cascade strategy.

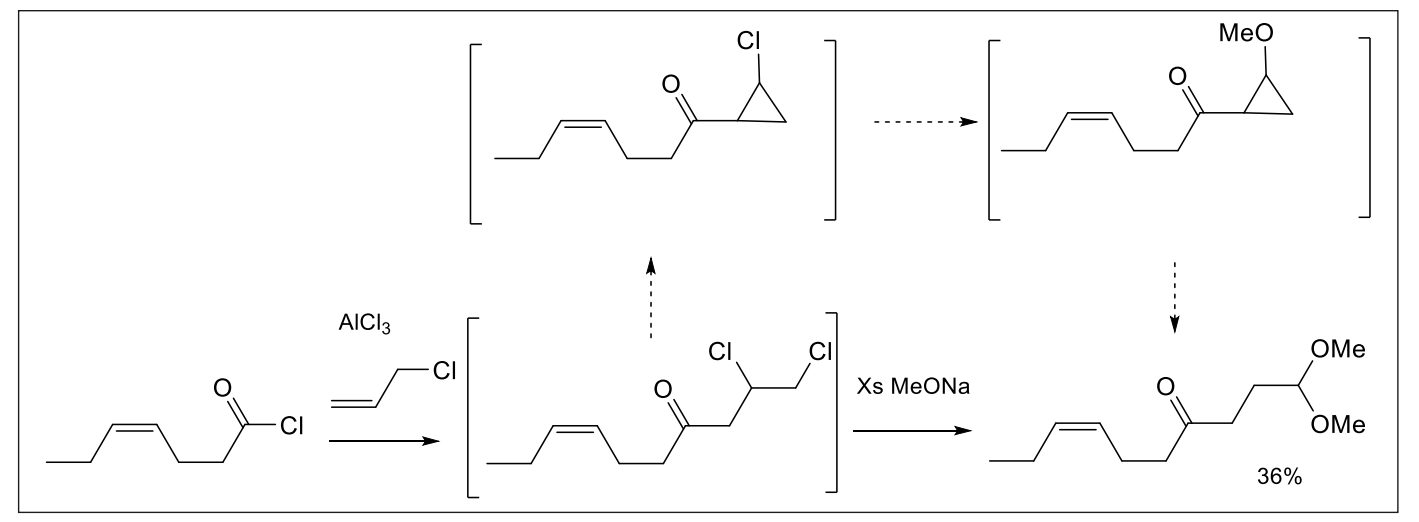

Scheme 17. Our approach based on Umpolung Stetter reaction, followed by full reduction/oxidation.

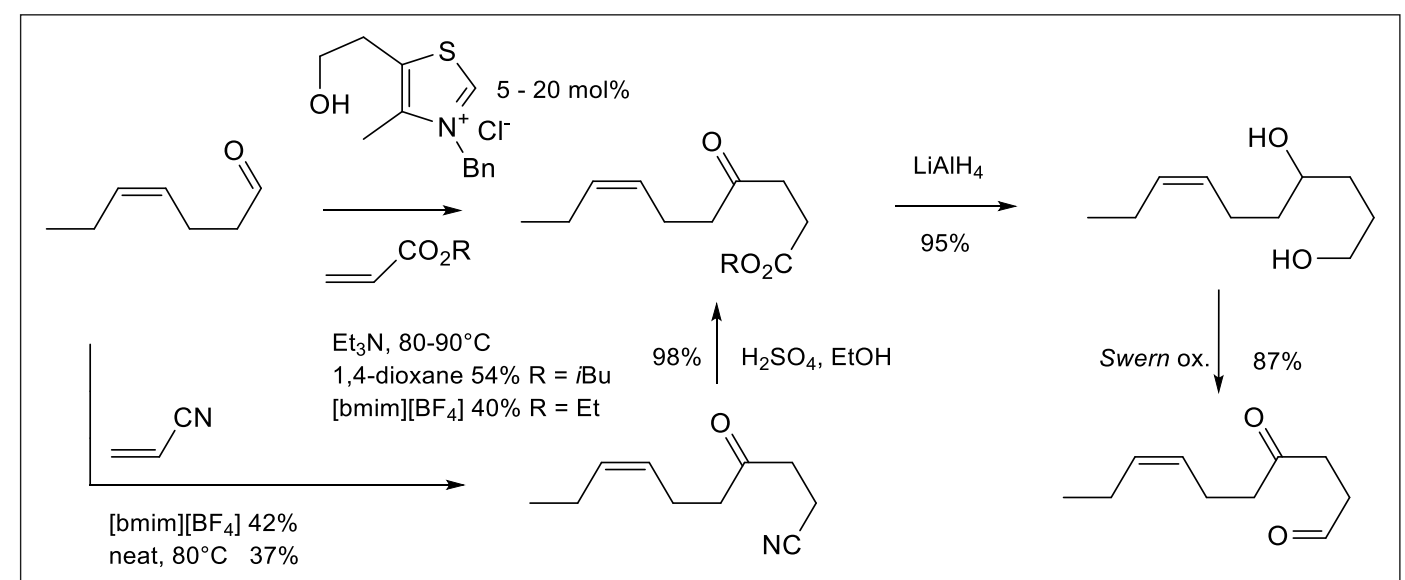

Scheme 18. Our modified onepot Stetter reaction/acetalization, followed by a one-pot reduction/ hydrolysis.

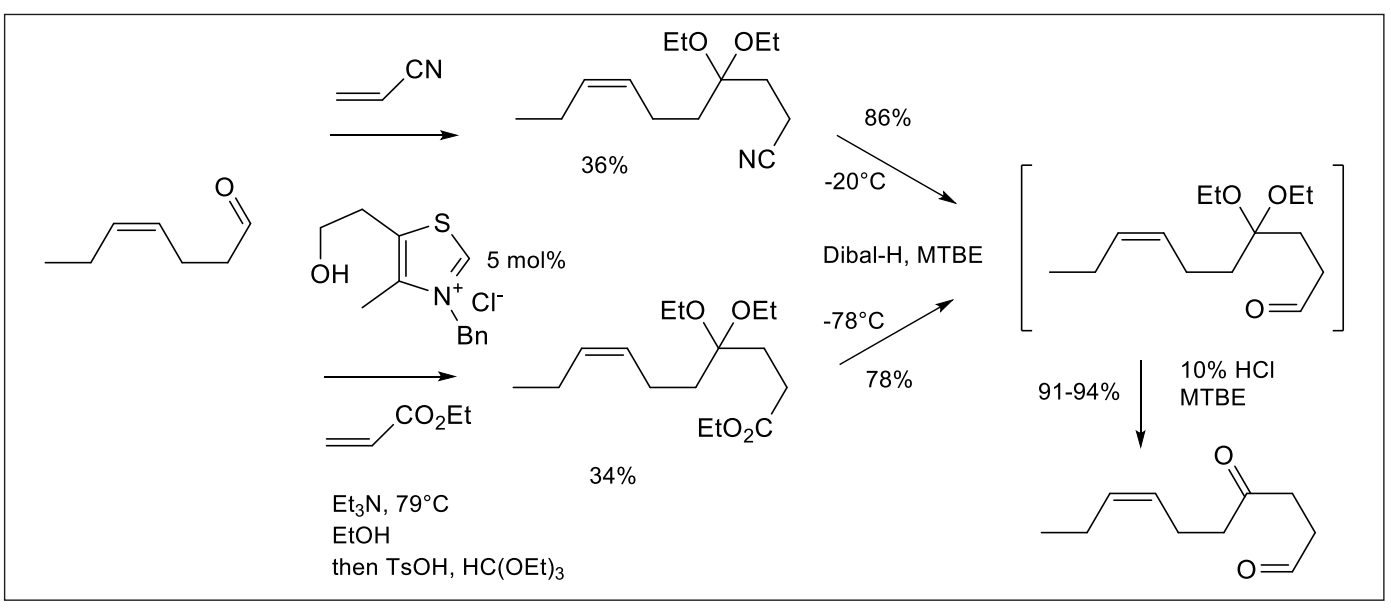


strong acidic conditions, ${ }^{[65]}$ although the final reduction is eventually possible using either $\mathrm{NaI} / \mathrm{HCl} /$ acetone conditions, ${ }^{[66 a, b, d]}$ or alternatively, Lindlar hydrogenation ${ }^{[66 \mathrm{c}]}$ after dioxirane/acetone oxidation. ${ }^{[66 c, 67]}$

We thus returned to the Grignard strategy and added (3Z)hexenylMgCl to succinimide (Scheme 19). The best conditions were obtained, after initial deprotonation with one equivalent of $\mathrm{MeMgCl}$, by analogously applying the conditions reported by Evans et al. in non-aggregating $\mathrm{CH}_{2} \mathrm{Cl}_{2}$ (67\% yield). ${ }^{[68]} \mathrm{A}$ series of standard ether solvents were tested, but with lower yields. The intermediate Grignard heterocyclic adduct may be either isolated, or used crude, for either quantitative $\mathrm{NaBH}_{4}$ reduction to the corresponding lactam, or acidic methanolysis to afford the desired keto-ester, as a known precursor of the corresponding $\gamma$-jasmolactone. ${ }^{[16 b]}$

It is noteworthy that this sequence may also be extended to the homologous $\delta$-jasmo-lactone by identical Grignard addition to glutarimide. Treatment of the keto-ester in refluxing xylene with $\mathrm{MeONa}$, according to a Japanese patent, ${ }^{[69]}$ promoted the intramolecular Claisen condensation, so that the resulting enolate could be quenched either under acidic conditions, to afford the cyclic keto-enol, or with an alkylating agent, such as $\mathrm{Me}_{2} \mathrm{SO}_{4}$, to afford the corresponding keto-methylenol ether. Alternatively the enol form could also eventually be transposed by treatment with $\mathrm{TsCl}$ to the corresponding tosylate. At this point we faced two possible strategies, one consisted of 1,2-reduction of the keto-methylenol ether with PMHS, in the catalytic presence of $\mathrm{Zn}$ (2-Et-hexanoate) ${ }_{2}$, according to Mimoun's protocol, ${ }^{, 70]}$ towards the former key $(Z)$-2-(pent-2-en-1-yl)cyclopent2-en-1-one. This reduction could also be performed, in a less efficient manner, with $\mathrm{NaBH}_{4}$ onto the corresponding tosylate. ${ }^{[71]}$ The second option consisted of following Oberhänsli's strategy, ${ }^{[72]}$ by inverting the sequence, namely by 1,4 -addition of dimethylmalonate, then decarbomethoxylation. The last 1,4-reduction was then performed by a $\mathrm{Cu}-\mathrm{H}$ species, generated from $\mathrm{NaBH}_{4}$ and $\mathrm{Cu}\left(2\right.$-Et-hexanoate) ${ }_{2} \cdot{ }^{[70]}$ Methyl jasmonate was thus isolated in 44\% yield as a 64:36 trans/cis mixture. An analogous final 1,4-reduction could also be performed on the dehydro-side chain analogue, ${ }^{[69]}$ affording in $53 \%$ yield a $67: 33$ mixture of diastereoisomers.

\section{Conclusion.}

We have drastically simplified and improved several previously described syntheses by reducing the original sequences from one to five steps, thus rendering, for example, Mane's synthesis significantly more concise. We also performed several independent or optically active approaches, for this route scouting study. More than five thousand methyl jasmonate derivatives are actually known in the literature, including a large panel of volatile analogues. This molecule is thus ideal for Structure-Odor Relationships studies, and we shall soon report on some simpler effective new ingredients, as actually none of them is superior to the natural product, in terms of strength and radiance.

\section{Acknowledgements}

We are indebted to Drs. A. A. Birkbeck and J. M. Lem for fruitful discussions and proof reading.

\section{Supplementary material}

Procedures and analytical data of unreported intermediates, as well as additional references.

Received: January 14, 2019

[1] L. Ruzicka, M. Pfeiffer, Helv, Chim. Acta 1933, 16, 1208

[2] a) E. Demole, E. Lederer, to Firmenich SA, CH 382731, 1960; b) E. Demole, E. Lederer, to Firmenich SA, CH 490313, 1960, Chem. Abstr. 1970, 73 , 109368.

[3] a) E. P. Demole, E. Lederer, D. Mercier, Helv. Chim. Acta 1962, 45, 675; b) E.P. Demole, E. Lederer, D. Mercier, Helv. Chim. Acta 1962, 45, 685; c) E. P. Demole, M. Stoll, Helv. Chim. Acta 1962, 45, 692.

[4] R. Crabalona, Compt. Rend. Acad. Sci. 1967, 264, 2074

[5] a) R. Nishida, T. E. Acree, J. Agric. Food Chem. 1984, 32, 1001; b) R. Näf, $35^{\text {th }}$ Int. Symp. Essent. Oils 2004, Taormina, Italy; c) R. Näf, in 'Citrus Oils Composition, Advanced Analytical Techniques, Contaminants, and Biological Activity', Eds G. Dugo, L. Mondello, CRC Press, London, 2001, p 463.

[6] R. Kaiser, J. Essent. Oil Res. 1991, 3, 129.

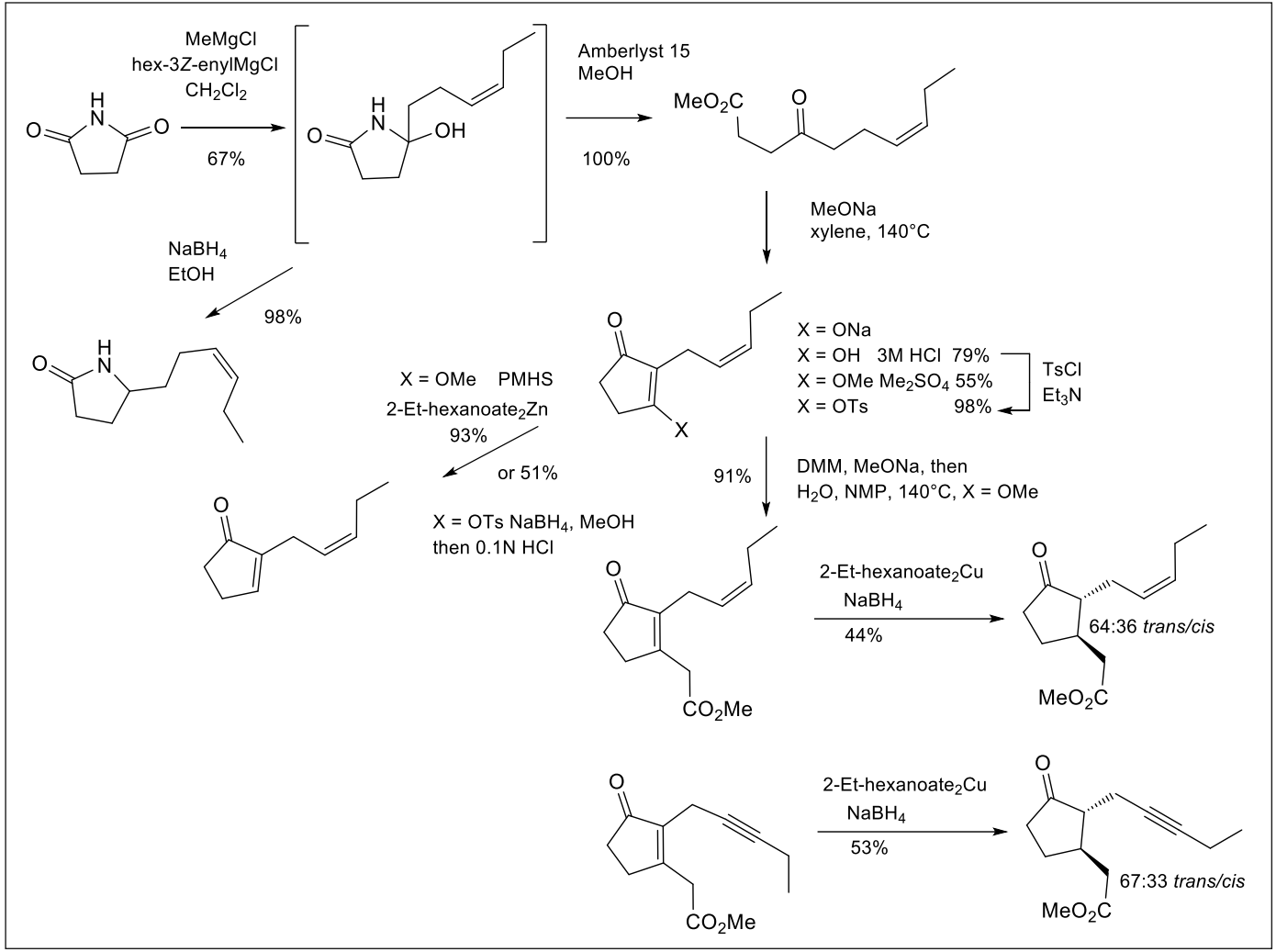

Scheme 19. Grignard addition to succinimide, followed by methanolysis, Claisen condensation with in situ O-alkylation, and catalytic $\mathrm{Zn}(\mathrm{II}) / \mathrm{PMHS}$ 1,2-reduction, as priviledged strategy over the DMM Michael addition, then $\mathrm{Cu}-\mathrm{H}$ 1,4-reduction, according to the present work. 
[7] a) W. Renold, R. Näf-Muller, U. Keller, B. Willhalm, G. Ohloff, Helv. Chim Acta 1974, 57, 1301; b) L. G. Kharebava, A. G. Tsirgvava, Chai. Kult'tura I Pr-vo, Tbilisi 1979, 2, 26; c) A. G. Sardzhveladze, I. A. Chernavina, L. G. Kharebava, Subtrop. Kult. 1985, 6, 78; d) T. Yamanishi, M. Kawatsu, T. Yokoyama, Y. Nakatani, Agric. Biol. Chem. 1973, 37, 1075; e) A. Kobayashi, M. Kawamura, Y. Yamamoto, K. Shimizu, K. Kubota, T. Yamanishi, Agric. Biol. Chem. 1988, 52, 2299.

[8] a) M. H. Beale, J. L. Ward, Nat. Prod. Rep. 1998, 15, 533; b) O. Miersch, R. Kramell, B. Parthier, C. Westernack, Phytochemistry 1999, 50, 353.

[9] a) W. Boland, J. Hopke, J. Donath, J. Nüske, F. Bublitz, Angew. Chem. Int Ed. 1995, 34, 1600; b) G. Sembdner, B. Parthier, Annu. Rev. Plant. Physiol. Plant Mol. Biol. 1993, 44, 569; c) B. Parthier, Bot. Acta 1991, 104, 446; e) M. del Mar Caja, G. P. Blanch, M. L. Ruiz del Castillo, J. Agric. Food Chem. 2008, 56, 5475.

[10] E. E. Farmer, C. A. Ryan, Proc. Natl. Acad. Sci. USA 1990, 87, 7713.

[11] S. Katayama, H. Iwabuchi, Food, Food Ingred. J, Jpn. 2002, 202, 55.

[12] a) B. A. Vick, D. C. Zimmermann, Biochem. Biophys. Res. Commun. 1983, 111, 470; b) B. A. Vick, D. C. Zimmermann, Plant Physiol. 1984, 75, 458. For reviews, see c) J. Léon, J. J. Sànchez-Serrano, Plant Physiol. Biochem. 1999, 37, 373; d) E. E. Farmer, E. Alméras, V. Krishnamurthy, Curr. Opin. Plant Biol. 2003, 6, 372

[13] a) T. C. Baker, R. Nishida, W. L. Roelofs, Science 1981, 214, 1359; b) R. Nishida, T. E. Acree, Chem. Eng. News, 19 Sept. 1983, 34; c) R. Nishida, T. E. Acree, H. Fukami, Agric. Biol. Chem. 1985, 49, 769; d) T. E. Acree, R. Nishida, H. Fukami, J. Agric. Food Chem. 1985, 33, 425; e) Y. Koda, Y. Kikuta, T. Kitihara, T. Nishi, K. Mori, Phytochemistry 1992, 31, 1111.

[14] a) E. P. Demole, 'Fragrance Chemistry: The Science of the Smell', Ed. E. T. Theimer, Academic Press, New York, 1982, p. 349; b) Inst. Org. Chem. J. W. Goethe Univ., Synform 1985, 3, 125; c) T. K. Sarkar, B. K. Ghorai, J. Indian Chem. Soc. 1999, 76, 693; d) C. Chapuis, Helv. Chim. Acta 2012, 95, 1479; e) C. Chapuis, Perfum. Flavor. 2011, 36, 36.

[15] G. H. Büchi, B. Egger, J. Org. Chem. 1971, 36, 2021.

[16] a) C. Celli, M. Plattier \& P. J. Teisseire, to Roure Bertrand \& J. Dupont, Ger. Offen 2260447, 1973, Chem. Abstr. 1973, 79, 42032y; b) P. Dubs, R. Stüssi, Helv. Chim. Acta 1978, 87, 990; c) P. Dubs, R. Stüssi, Helv. Chim. Acta 1978, 87, 998 .

[17] F. Johnson, K. G. Paul, US 4014919, 1977, Chem. Abstr. 1976, 84, 59783.

[18] a) K. G. Hampton, J. J. Christie, J. Org. Chem. 1975, 40, 3887; b) H. Kimura, S. Miyamoto, H. Shinkai, T. Kato, Chem. Pharm. Bull. 1982, 30, 723; c) E. Holz, P. Langer, Synth. Commun. 2007, 37, 2959.

[19] F. Johnson, K. G. Paul, D. Favara, R. Ciabatti, U. Guzzi, J. Am. Chem. Soc. 1982, 104, 2190

[20] a) Y. T. Liu, J. Q. Chen, L. P. Li, X. Y. Shao, J. H. Xie, Q. L. Zhou, Org. Lett. 2017, 19, 3231; b) Y. T. Liu, L. P. Li, J. H. Xie, Q. L. Zhou, Angew. Chem. Int. Ed. 2017, 56, 12708; c) anonymous, to Gruppo Lepetit, GB 1494758, 1975, Chem. Abstr. 1976, 84, 135174; d) P. F. Johnson, D. Ferava, J. Am. Chem. Soc. 1976, 98, 1285; e) P. A. Magriotis, F. Johnson, J. Org. Chem. 1984, 49, 1460; f) V. Berl, G. Helmchen, S. Preston, Tetrahedron Lett. 1994, 35, 233; g) J. H. Xie, X. Y. Liu, X. H. Yang, J. B. Xie, L. X. Wang, Q. L. Zhou, Angew. Chem. Int. Ed. 2012, 51, 201.

[21] K. Weinges, H. Gethöfter, U. Huber-Patz, H. Rodewald, H. Imgartinger, Lieb. Ann. Chem. 1987, 361 .

[22] H. Kuritani, Y. Takaoka, K. Shingu, J. Org. Chem. 1979, 44, 452.

[23] S. Torii, H. Tanaka, T. Mandai, J. Org. Chem. 1975, 40, 2221.

[24] a) Inst. Org. Chem. J. W. Goethe Univ., Synform 1983, 1, 33; b) G. Rosini, R. Ballini, M. Petrini, P. Sorrenti, Tetrahedron 1984, 40, 3809; c) R. Ballini, M. Petrini, E. Marotta, Synth. Commun. 1989, 19, 575; d) N. W. A. Geraghty, N. M. Morris, Synthesis 1989, 603.

[25] S. Chatterjee, E. Negishi, J. Organometal. Chem. 1985, 285, C1.

[26] a) G. Cahiez, B. Laboue, Tetrahedron Lett. 1992, 33, 4439; b) G. Cahiez, B. Laboue, Tetrahedron Lett. 1989, 30, 7369; c) G. Cahiez, M. Alami, Tetrahedron 1989, 45, 4163.

[27] N. Kornblum, W. J. Jones, G. J. Anderson, J. Am. Chem. Soc. 1959, 81, 4113

[28] I. Matsuda, S. Murata, Y. Izumi, J. Org. Chem. 1980, 45, 237.

[29] S. Mukaiyama, J. Inanaga, M. Yamaguchi, Bull. Chem. Soc. Jpn. 1981, 54, 2221

[30] F. Naef, R. Decorzant, Helv. Chim. Acta 1978, 61, 2524.

[31] V. L. Heasley, G. E. Heasley, S. K. Taylor, C. L. Frye, J. Org. Chem. 1970, 35, 2967.

[32] a) H. Y. Cho, J. P. Morken, J. Am. Chem. Soc. 2008, 130, 16140; b) C. H Schuster, B. Li, J. P. Morken, Angew, Chem. Int. Ed. 2011, 50, 7906.

[33] K. H. Schulte-Elte, B. Willhalm, G. Ohloff, Angew. Chem. Int. Ed. 1969, 8, 985.

[34] C. Chapuis, E. Walther, F. Robvieux, C.-A. Richard, L. Goumaz, J.-Y. de Saint Laumer, Helv. Chim. Acta 2016, 99, 95.

[35] a) H. Kataoka, T. Yamada, K. Goto, J. Tsuji, Tetrahedron 1987, 43, 4107; b) J. Tsuji, I. Shimizu, H. Kataoka, Y. Mitsuda, K. Goto, to Nippon Zeon Co, US 4496766, 1985, Chem. Abstr. 1984, 100, 67888.

[36] C. Fehr, J. Galindo, O. Etter, E. Ohleyer, Chimia 1999, 53, 376

[37] C. Fehr, J. Galindo, Angew. Chem. Int. Ed. 2000, 39, 569.

[38] a) J. Q. Liu, H. C. Wu, E. J. Corey, Org. Lett. 2005, 7, 1415; b) C. Waldorff, T. Johann, B. Rössler, H. Hibst, J. H. Teles, S. Storck, J. Klein, to BASF WO
2005/73157A2, Chem. Abstr. 2005, 143, 195574; c) Y. Shvo, A. H. I. Arisha, J. Org. Chem. 1998, 63, 5640.

[39] C. Chapuis, G. Büchi, H. Wüest, Helv. Chim. Acta, 2005, 88, 3069.

[40] O. Miersch, Zeitschr. Naturforsch. (B), 1991, 46, 1727

[41] a) P. J. Brown, D. Neville Jones, M. Akram Khan, N. A. Meanwell, Tetrahedron Lett. 1983, 24, 405; b) P. J. Brown, D. Neville Jones, M. Akram Khan, N. A. Meanwell, P. J. Richards, J. Chem. Soc. Perkin Trans. 1, 1984, 2049.

[42] C. Chapuis, C. Cantatore, J.-Y. de Saint Laumer, Helv. Chim. Acta 2006, 89 , 1258 .

[43] a) T. Kitahara, K. Mori, M. Matsui, M. Iwamoto, Y. Takagi, Y. Warita, Agric. Biol. Chem. 1982, 46, 1369; b) C. W. Bird, H. I. Buttler, M. P. L. Caton, E. C. J. Coffee, C. J. Hardy, T. W. Hart, H. J. Mason, Tetrahedron Lett. 1985, 26 4101; c) H. J. Liu, J. Hsing, W. M. Feng, Synth. Commun. 1987, 17, 1777; d) M. E. Jung, D. Ho, H. V. Chu, Org. Lett. 2005, 7, 1649.

[44] J. M. Lem, K. P. Vanhessche, C. Mahaim, to Firmenich SA, WO 2007/056129, Chem. Abstr. 2007, 146, 521481

[45] a) V. Rautenstrauch, J. J. Riedhauser, to Firmenich SA, WO 9600206, 1996 Chem. Abstr. 1996, 124, 232126; b) B. Winter, C.Chapuis, R. Brauchli, J.-Y. de Saint Laumer, Helv. Chim. Acta 2013, 96, 246.

[46] a) D. A. Dobbs, K. P. Vanhessche, E. Brazi, V. Rautenstrauch, J.-Y. Lenoir, J.-P. Genet, J. Wiles, S. H. Bergens, Angew. Chem. Int. Ed. 2000, 39, 1992; b) J. A. Wiles, S. H. Bergens, K. P. M. Vanhessche, D. A. Dobbs, V. Rautenstrauch, Angew. Chem. Int. Ed. 2001, 40, 914; c) V. Rautenstrauch, Org. Process Res. Dev. 2012, 16, 1185.

[47] a) J. S. Sharley, I. R. Baxendale, F. E. Espinos, A. M. Collado Perez, F. I. Fernandez, J. Sanchez Quesada, to IFF, WO 2018/183788, Chem. Abstr. 2018, 169, 408405; b) I. R. Baxendale, J. S. Sharley, A. F. Miranda, A. M. Collado Pérez, to IFF, US 2017/174607, Chem. Abstr. 2017, 167, 100651.

[48] K. Crawford, V. Rautenstrauch, A. Uijttewaal, Synlett. 2001, 1127.

[49] C. Chapuis, C.-A. Richard, Helv. Chim. Acta 2018, 101, e1800063.

[50] a) H. Kiyota, Y. Yoneta, T. Oritani, Phytochem. 1997, 46, 983; b) S. Torii, H. Tanaka, T. Kudai, S. Watanabe, Chem. Lett. 1979, 147.

[51] a) T. Perrard, J.-C. Plaquevent, J.-R. Desmurs, D. Hébrault, Org. Lett. 2000, 2, 2959; b) B. Thierry, T. Perrard, C. Audouard, J. C. Plaquevent, D. Cahard, Synthesis 2001, 1742; c) S. Piovesana, D. M. S. Schietroma, L. G. Tulli, M R. Monaco, M. Bella, Chem. Commun 2010, 46, 5160; d) G. Zhang, D. Yang, to Beijing Ansheng Ruili Sci. \& Techn. Co. CN 106946705, 2017 Chem. Abstr. 2017, 167, 306642; e) T. Ebata, K. Matsumoto, H. Matsushita, Heterocycles 1994, 38, 2231.

[52] P. Jaunky, J. Buirey, C. Mahaim, Flav. Frag. J. 2017, 32, 388

[53] a) P. L. Barrick, A. A. Pavlic, to Du Pont de Nemours Co, US 2506571 , 1948, Chem. Abstr. 1950, 44, 38196; b) V. B. Del'nik, S. S. Kagna, M. G. Katsnel'son, M. G. Leenson, J. Appl. Chem. USSR, 1985, 58, 1248; c) R. A Dubois, P. E. Garrou, J. Organomet. Chem. 1983, 241, 69.

[54] O. G. Kulinkovich, I. G. Tishchenko, V. L. Sorokin, Zhurn. Organ. Khimii, 1986, 22, 1825 .

[55] a) H. Stetter, H. Kuhlmann, Synthesis, 1975, 379; b) H. Stetter, W. Basse, K Wiemann, Chem. Ber. 1978, 111, 431; c) L. Novak, G. Baan, J. Marosfalvi, C. Csaba, Tetrahedron Lett. 1978, 5, 487 .

[56] S. Anjaiah, S. Chandrasekhar, R. Grée, Adv. Synth. Catal. 2004, 346, 1329.

[57] M. J. Damha, M. Hassler, T. H. Chan, M. R. Nandyala, R. A. Donga, to Mc Gill Univ. \& Hong Kong Polytechnic Univ. US 9920084, 2018, Chem. Abstr. 2016, 167, 176296.

[58] a) M. Triantafyllakis, M. Tofi, T. Montagnon, A. Kouridaki, G. Vassilikogiannakis, Org. Lett. 2014, 16, 3150; b) Anonymous, to Am. Cyanamid Co. US 4958037, 1990, Chem. Abstr. 1987, 107, 39502.

[59] P. Weyerstahl, A. Schenk, H. Marschall, Lieb. Ann. Chem. 1995, 1849.

[60] H. J. Wu, C. H. Lin, J. Org. Chem. 1996, 61, 3820.

[61] a) B. M. Paz, L. Klier, L. Naesborg, V. H. Lauridsen, F. Jensen, K. A Jorgensen, Chem. Eur. J. 2016, 22, 16810; b) L. Eschen-Lippold, T. Draeger, A. Teichert, L. Wessjohann, B. Westermann, S. Rosahl, N. Arnold, J. Agric. Food Chem. 2009, 57, 9607; c) P. Jakubec, D. Berkes, A. Kalarovic, F. Povasanec, Synthesis 2006, 4032; d) J. Choi, J. M. Laird, R. G. Salomon, J. Bioorg. Med. Chem. 2011, 19, 580, e) Y. Kobayashi, K. Kishihara, K. Watatani, Tetrahedron Lett. 1996, 37, 4385; f) Y. Kobayashi, M. Nakano, G B. Kumar, K. Kishihara, J. Org. Chem 1998, 63, 7505.

[62] a) K. T. Potts, R. Robinson, J. Chem. Soc. 1955, 2675; b) J. Levisalles, Bull. Soc. Chim. Fr. 1957, 1009; c) M. B. Floyd, J. Org. Chem. 1978, 43, 1641; d) M. D’Auria, A. De Mico, G. Piancatelly, A. Scettry, Tetrahedron 1982, 38 , 1661; e) F. D'Onofrio, G. Prancatelli, M. Nicolai, Tetrahedron 1995, 51, 4083.

[63] a) J. M. J. Verlaak, A. J. H. Klunder, B. Zwanenburg, Tetrahedron Lett. 1982 23, 5463; b) G. Heinisch, T. Huber, J. Heterocycl. Chem. 1989, 26, 1787.

[64] a) G. Schenck, Just. Lieb. Annal. Chem. 1953, 584, 156; b) B. L. Feringa, R. J. Butselaar, Tetrahedron Lett. 1982, 23, 1941; c) D. Kalaitzakis, M. Triantafyllakis, I. Alexopoulou, M. Sofiadis, G. Vassilikogiannakis, Angew. Chem. Int. Ed. 2014, 53, 13201.

[65] a) C. Harries, Chem. Ber. 1898, 31, 37; b) A. Madder, K. Hoogewijs, A Deceuninck, L. Carrette, Univ. Gent, US 9290537, 2016, Chem. Abstr. 2012 157, 155294.

[66] a) M. D'Auria, G. Piancatelli, A. Scettri, Synthesis 1980, 245; b) F. D'Onofrio, G. Piancatelli, M. Nicolai, Tetrahedron 1995, 51, 4083; c) K. 
Krähenbühl, S. Picasso, P. Vogel, Helv. Chim. Acta 1998, 81, 1439; N. R. Da Silva, D. C. De Magalhaes, Synth. Commun. 1999, 29, 1477.

[67] F. D. Boyer, C. L. Descoins, G. V. Thanh, C. Descoins, T. Prange, P. H. Ducrot, Eur. J. Org. Chem. 2003, 1172.

[68] a) D. A. Evans, E. W. Thomas, R. E. Cherpeck, J. Am. Chem. Soc. 1982, 104, 3695; b) N. Hucher, A. Daich, B. Decroix, Org. Lett. 2000, 1201; c) A. Chihab-Eddine, A. Daich, A. Jilale, B. Decroix, Heterocycles 2002, 58, 449; d) Y. P. Ruan, M. D. Chen, M. Z. He, X. Zhou, P. Q. Huang, Synth. Commun. 2004, 34, 853; e) L. J. Jiang, B. Teng, J. F. Zheng, J. L. Ye, P. Q. Huang, Tetrahedron 2010, 66, 172; f) C. Lindemann, C. Schneider, Synthesis 2016, 48,828 .
[69] K. Shimuzu, F. Matsushita, to Asahi Kasei Chem. Corp. US 7897802, 2011, Chem. Abstr. 2007, 146, 142304.

[70] H. Mimoun, J. Org. Chem. 1999, 64, 2582.

[71] F. A. Lakhvich, F. S. Pashkovskii, L. G. Lis, J. Org. Chem. USSR, 1992, 28, 2004.

[72] a) P. Oberhänsli to Givaudan SA, Ger. Offen. 2008833, 1969, Chem. Abstr. 1970, 73, 109364e; b) D. Anderson, G. Fràter, to Givaudan-Roure SA, EP 953562, 1999, Chem. Abstr. 1999, 131, 324143. 